\title{
Synthesis of graphene
}

\author{
Md. Sajibul Alam Bhuyan ${ }^{1}$ - Md. Nizam Uddin ${ }^{1} \cdot$ Md. Maksudul Islam ${ }^{2}$. \\ Ferdaushi Alam Bipasha ${ }^{3}$ Sayed Shafayat Hossain ${ }^{1}$
}

Received: 23 March 2015/Accepted: 13 December 2015/Published online: 9 February 2016

(C) The Author(s) 2016. This article is published with open access at Springerlink.com

\begin{abstract}
Graphene, a two-dimensional material of $\mathrm{sp}^{2}$ hybridization carbon atoms, has fascinated much attention in recent years owing to its extraordinary electronic, optical, magnetic, thermal, and mechanical properties as well as large specific surface area. For the tremendous application of graphene in nano-electronics, it is essential to fabricate high-quality graphene in large production. There are different methods of generating graphene. This review summarizes the exfoliation of graphene by mechanical, chemical and thermal reduction and chemical vapor deposition and mentions their advantages and disadvantages. This article also indicates recent advances in controllable synthesis of graphene, illuminates the problems, and prospects the future development in this field.
\end{abstract}

Keywords Chemical vapor deposition (CVD) Epitaxial $\cdot$ Mechanical exfoliation $\cdot$ PECVD reduction graphene oxide (RGO) · Unzipping method

Md. Sajibul Alam Bhuyan

sajibul.alam.1005057@gmail.com

Md. Maksudul Islam

maksudkhandakar@gmail.com

Ferdaushi Alam Bipasha

ferdaushi.bipasha93@gmail.com

1 Department of Mechanical Engineering, Khulna University of Engineering and Technology, Khulna 9203, Bangladesh

2 Department of Industrial Engineering and Management, Khulna University of Engineering and Technology, Khulna 9203, Bangladesh

3 Department of Mechanical Engineering, Bangladesh University of Engineering and Technology, Dhaka 1000, Bangladesh

\section{Introduction}

Carbon is a ubiquitous material that has been ever found whereas the epoch making material graphene is also an allotropy of carbon. Actually graphene is a two-dimensional, single-layer sheet of $\mathrm{sp}^{2}$ hybridized carbon atoms and has arrested enormous attention and research motives for its versatile properties. In $\mathrm{sp}^{2}$ hybridized bond, the inplane $\sigma_{\mathrm{C}-\mathrm{C}}$ bond is one of the strongest bonds in materials and the out-of-plane is $\pi$ bond, which imparts to a delocalized network or array of electrons resulting electron conduction by providing weak interaction among graphene layers or between graphene and substrate. Graphene is a material which has a large theoretical specific surface area $\left(2630 \mathrm{~m}^{2} \mathrm{~g}^{-1}\right)$, high intrinsic mobility $\left(200,000 \mathrm{~cm}^{2}\right.$ $\left.\mathrm{v}^{-1} \mathrm{~s}^{-1}\right),[1,2]$ high Young's modulus $(\sim 1.0 \mathrm{TPa})[3]$ and thermal conductivity $\left(\sim 5000 \mathrm{Wm}^{-1} \mathrm{~K}^{-1}\right), \quad[4]$ and its optical transmittance $(\sim 97.7 \%)$ and good electrical conductivity merit attention as well as ability to with stand current density of $108 \mathrm{~A} / \mathrm{cm}^{2}$ [5], for applications such as for transparent conductive electrodes [6, 7] among many other potential applications. However, its applicability cannot be effectively realized unless superficial techniques to synthesize high-quality, large-area graphene are developed in a cost effective way. Besides, a great deal of effort is required to develop techniques for modifying and opening its band structure so as to make it a potential replacement for silicon in future electronics. Graphene has been experimentally studied for over 40 years [8-14] and measurements of transport properties in micromechanically exfoliated layers [15], of graphene grown on $(\mathrm{SiC})$ [16], large-area graphene grown on copper $(\mathrm{Cu})$ substrates [17], as well as a variety of studies involving the use of chemically modified graphene (CMG) to make new materials [12-21]. 
The basic building blocks of all the carbon nanostructures are a single graphitic layer that is covalently functionalized $\mathrm{sp}^{2}$ bonded carbon atoms in a hexagonal honeycomb lattice which forms 3D bulk graphite, when the layers of single honeycomb graphitic lattices are stacked and bound by a weak van der Waals force. When the single graphite layer forms a sphere, it is well known as zerodimensional fullerene; when it is rolled up with respect to its axis, it forms a one-dimensional cylindrical structure called a carbon nanotube; and when it exhibits the planar 2D structure from one to a few layers stacked, it is called graphene. One graphitic layer is well known as monoatomic or single-layer graphene and two and three graphitic layers are known as bilayer and tri-layer graphene, respectively. More than 5 layer up to 10 layer graphene is generally called few layer graphene, and $\sim 20-30$ layer graphene is referred to as multilayer graphene, thick graphene, or nanocrystalline thin graphite [22].

\section{Synthesis of graphene}

Synthesis of graphene refers to any process for fabricating or extracting graphene, depending on the desired size, purity and efflorescence of the specific product. In the earlier stage various techniques had been found for producing thin graphitic films. Late 1970's carbon precipitated in the form of thin graphitic layers on transition metal surfaces [24, 25]. In 1975, few-layer graphite was synthesized on a single crystal platinum surface via chemical decomposition methods, but was not designated as graphene due to a lack of characterization techniques or perhaps due to its limited possible applications [26].

In those periods, their electronic properties never were investigated because of the difficulty in isolating and transferring them onto insulating substrates. But in the late 90's Ruoff and co-workers tried to isolate thin graphitic flakes on $\mathrm{SiO}_{2}$ substrates by mechanical rubbing of patterned islands on HOPG (Highly Oriented Pyrolytic Graphite) [13]. However there was no report on their electrical property characterization. Using a similar method this was later achieved in 2005 by Kim and co-workers and the electrical properties were reported [27]. But the real prompt advancement in graphene research began after Geim and co-workers first published their work of isolating graphene on to $\mathrm{SiO}_{2}$ substrate and measuring its electrical properties. After discovery of graphene in 2004 various techniques were developed to produce thin graphitic films and few layer graphene. The experimental evidence of 2D crystals came in 2004 [15] and 2005 [28] when thin flakes of graphene and other materials molybdenum disulphide, niobium diselenide and hexagonal boron nitride were first exfoliated from their bulk counterparts (Fig. 1). But

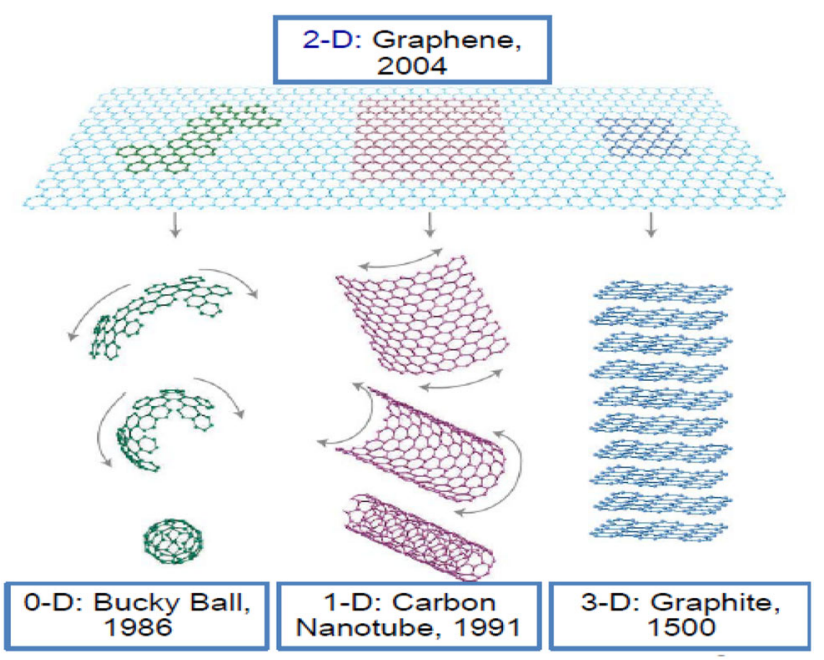

Fig. 1 Mother of all graphene forms. Graphene is a 2D building material for carbon material of all other dimensionalities. It can be wrapped up into 0D buckyballs, rolled into 1D nanotubes or stacked into 3D graphite [23]

graphene was first obtained in the form of small flakes of the order of several microns through mechanical exfoliation of graphite using scotch tape [4, 9]. Although this method gives the highest quality graphene but for mass production, fabrication method is needed that can synthesize wafer scale graphene.

In recent years, various techniques have been established for graphene synthesis. However, mechanical cleaving (exfoliation) [15], chemical exfoliation [29, 30], chemical synthesis [21], and thermal chemical vapor deposition (CVD) [31] synthesis are the most commonly used methods today. Some other techniques are also reported such as unzipping nanotube [32-34] and microwave synthesis [35]. Although mechanical exfoliation using AFM cantilever was found capable of fabricating few-layer graphene, the process limitation was thickness of graphene varies to $\sim 10 \mathrm{~nm}$, which is comparable to 30-layer graphene.

In chemical exfoliation method, solution dispersed graphite is exfoliated by inserting large alkali ions between the graphite layers. Chemical synthesis is the similar process which consists of the synthesis of graphite oxide, dispersion in a solution, followed by reduction with hydrazine. Similarly for carbon nanotube synthesis, catalytic thermal CVD has proved most significant process for large-scale graphene fabrication. When the thermal CVD process is carried out in a resistive heating furnace, it is known as thermal CVD, and when the process consists of plasmaassisted growth, it is called plasma enhanced CVD or PECVD. In this world as nothing is unmixed blessing, all synthesis methods have some drawbacks too depending upon the final application of graphene. For instance, the mechanical exfoliation method is capable of fabricating 


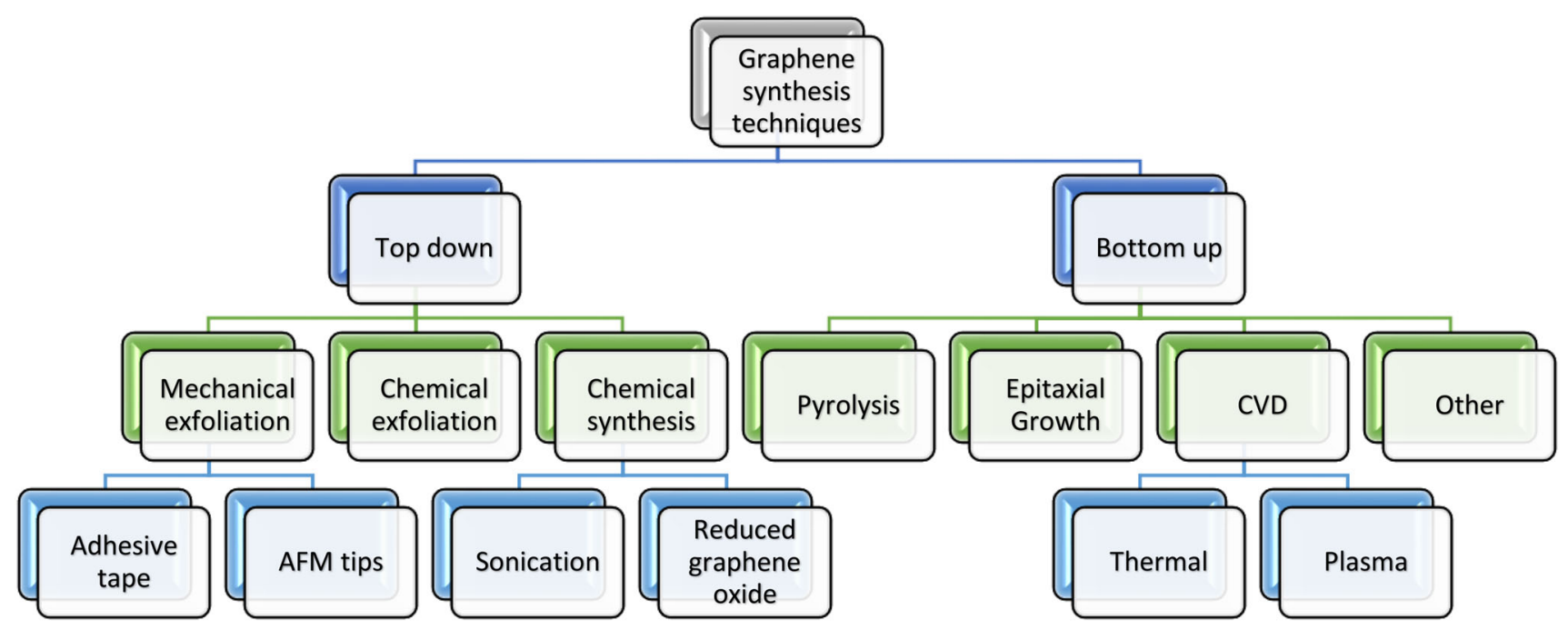

Fig. 2 A process flow chart of Graphene synthesis

monolayer to few-layers of graphene, but the reliability of obtaining a similar structure using this technique is quite insignificant. Furthermore, chemical synthesis processes are low temperature processes that make it more comfortable to fabricate graphene on multi-types of substrates at ambient temperature, particularly on polymeric substrate. But, large-area synthesized graphene produced in this process are non-uniform and dispersed. Again, graphene synthesized from reduced graphene oxides (RGOs) usually causes incomplete reduction of graphite oxide that results in the successive debasement of electrical properties depending on its degree of reduction. In contrast, thermal CVD methods are more advantageous for large-area device fabrication and favorable for future complementary metaloxide semiconductor (CMOS) technology by replacing $\mathrm{Si}$ [36]. Epitaxial graphene means thermal graphitization of a $\mathrm{SiC}$ surface which is another method of graphene synthesis, but the limitation of this method are high process temperature and inability to transfer on any other substrates. So, the thermal CVD method is unique because of producing uniform layer of thermally chemically catalyzed carbon atoms and that can be deposited onto metal surfaces and also can be transferred over a wide range of substrates.

An overview of graphene synthesis techniques is shown in the flow chart in Fig. 2.

\section{Bottom-up graphene}

The nature, average size, and thickness of the graphene sheets produced by different bottom-up methods as well as the advantages and disadvantages of each method are summarized in Table 1.

\section{Top-down graphene}

In top-down process, graphene or modified graphene sheets are produced by separation/exfoliation of graphite or graphite derivatives (such as graphite oxide (GO) and graphite fluoride. Table 2 may surmise some researcher's contribution.

\section{Mechanical exfoliation}

Mechanical exfoliation is may be the rarest and eminent process for extracting single layer graphene flakes on preferred substrates. It is the first recognized method of graphene synthesis. This is a top-down technique in nanotechnology, by which a longitudinal or transverse stress is created on the surface of the layered structure materials. Graphite is formed when mono-atomic graphene layers are stacked together by weak van der Waals forces. The interlayer distance and interlayer bond energy is $3.34 \AA$ and $2 \mathrm{eV} / \mathrm{nm}^{2}$, respectively. For mechanical cleaving, $\sim 300 \mathrm{nN} / \mu \mathrm{m}^{2}$ external force is required to separate one mono-atomic layer from graphite [27]. Stacking of sheets in graphite is the result of overlap of partially filled $\pi$ orbital perpendicular to the plane of the sheet (involving van der Waals forces). Exfoliation is the reverse of stacking; owing to the weak bonding and large lattice spacing in the perpendicular direction compared to the small lattice spacing and stronger bonding in the hexagonal lattice plane [58]. Graphene sheets of different thickness can indeed be obtained through mechanical exfoliation or by peeling off layers from graphitic materials such as highly ordered pyrolytic graphite (HOPG), single-crystal graphite, or 


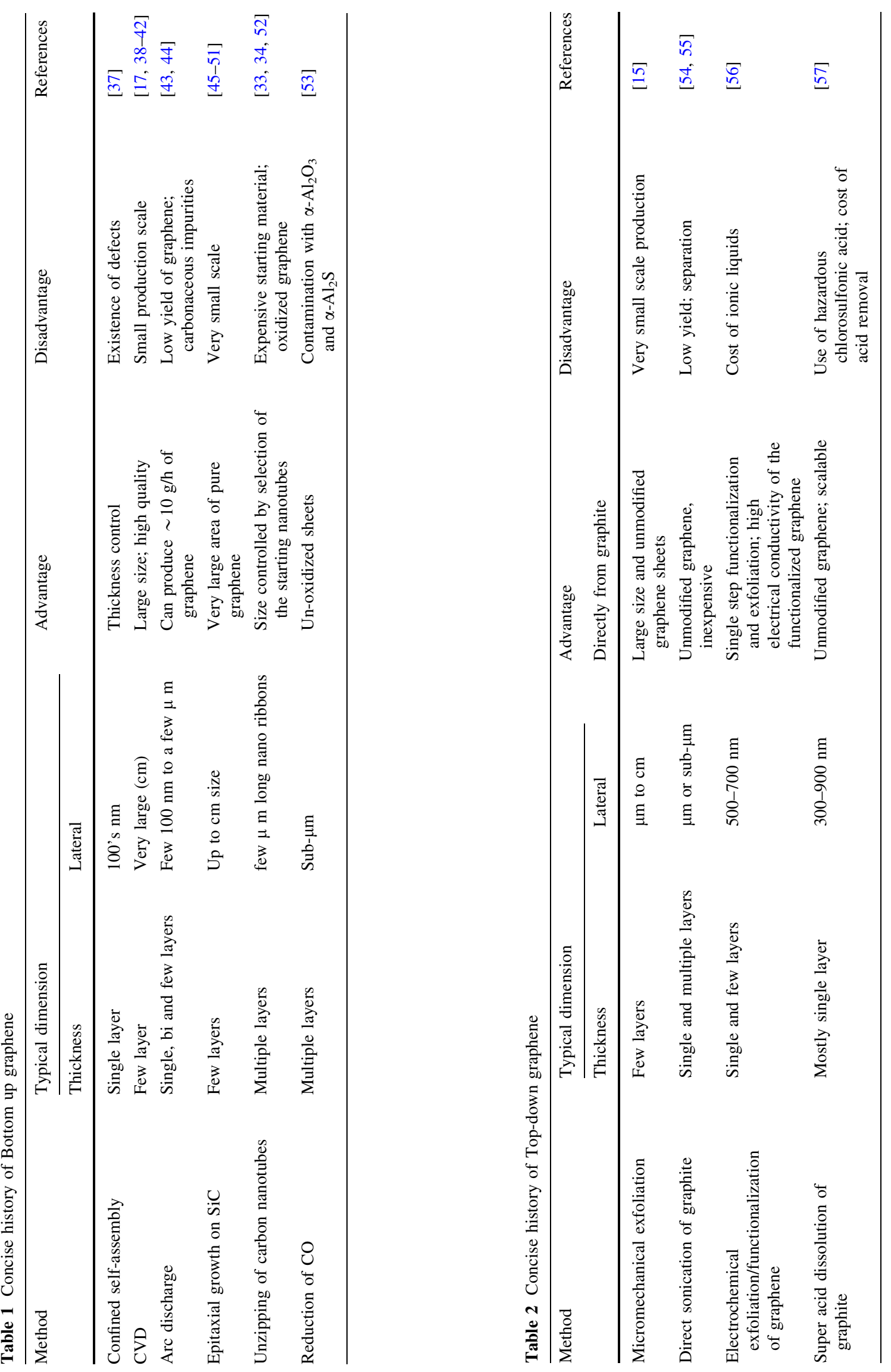


natural graphite [59-63]. This peeling/exfoliation can be done using a variety of agents like scotch tape [15], ultrasonication, [64] electric field [65] and even by transfer printing technique $[66,67]$, etc. In certain studies the HOPG has also been bonded to the substrate either by regular adhesives like epoxy resin [64, 68] or even by SAMs [69] to improve the yield of single and few layer graphene flakes. A recent study also demonstrates transfer printing of macroscopic graphene patterns from patterned HOPG using gold films [70]. It is by far the cheapest method to produce high-quality graphene. Graphene flakes obtained by mechanical exfoliation methods are usually characterized by optical microscopy, Raman spectroscopy and AFM. AFM analysis is carried out on exfoliated graphene to assess its thickness and number of layers. Finding a single layer flake is a fact of chance plus the yield of single and few layer graphene obtained by this method is more weaker and the flakes are randomly diffused on the substrate. Optical microscopy is another popular method of identifying single layer graphene. Depending on thickness graphene flakes give a characteristic color contrast on a thermally grown $\mathrm{SiO}_{2}$ layer of $300 \mathrm{~nm}$ thickness on top of $\mathrm{Si}$ wafers [71]. Raman spectroscopy is also carried out on graphene acquiring by mechanical exfoliation. It is the quickest and most precise method of identifying the thickness of graphene flakes and estimating its crystalline quality. This is because graphene exhibits characteristic Raman spectra based on number of layers present [72-74]. In this micromechanical exfoliation method, graphene is separated from a graphite crystal using adhesive tape. After peeling it off the graphite, multiple-layer graphene remains on the tape. By repeated peeling the multiple-layer graphene is cleaved into several flakes of few-layer graphene. Subsequently the tape is attached to the acetone substrate for detaching the tape. Finally one last peeling with an unused tape is performed. The obtained flakes vary substantially in size and thickness, where the sizes range from nanometers to several tens of micrometers for single-layer graphene, based on wafer. Single-layer graphene has an absorption rate of $2 \%$, nevertheless it is possible to see it under a light microscope on $\mathrm{SiO}_{2} / \mathrm{Si}$, due to interference effects [75].

Actually it is not easy to obtain larger amounts of graphene by this exfoliation method, not even taking into account the lack of sustainable flakes. The difficulty of this method is really low, nevertheless the graphene flakes require to be found on the substrate surface, which is labor exhaustive. The quality of the prepared graphene is very high with almost no defects. The graphene formed by these mechanical exfoliation methods was used for production of

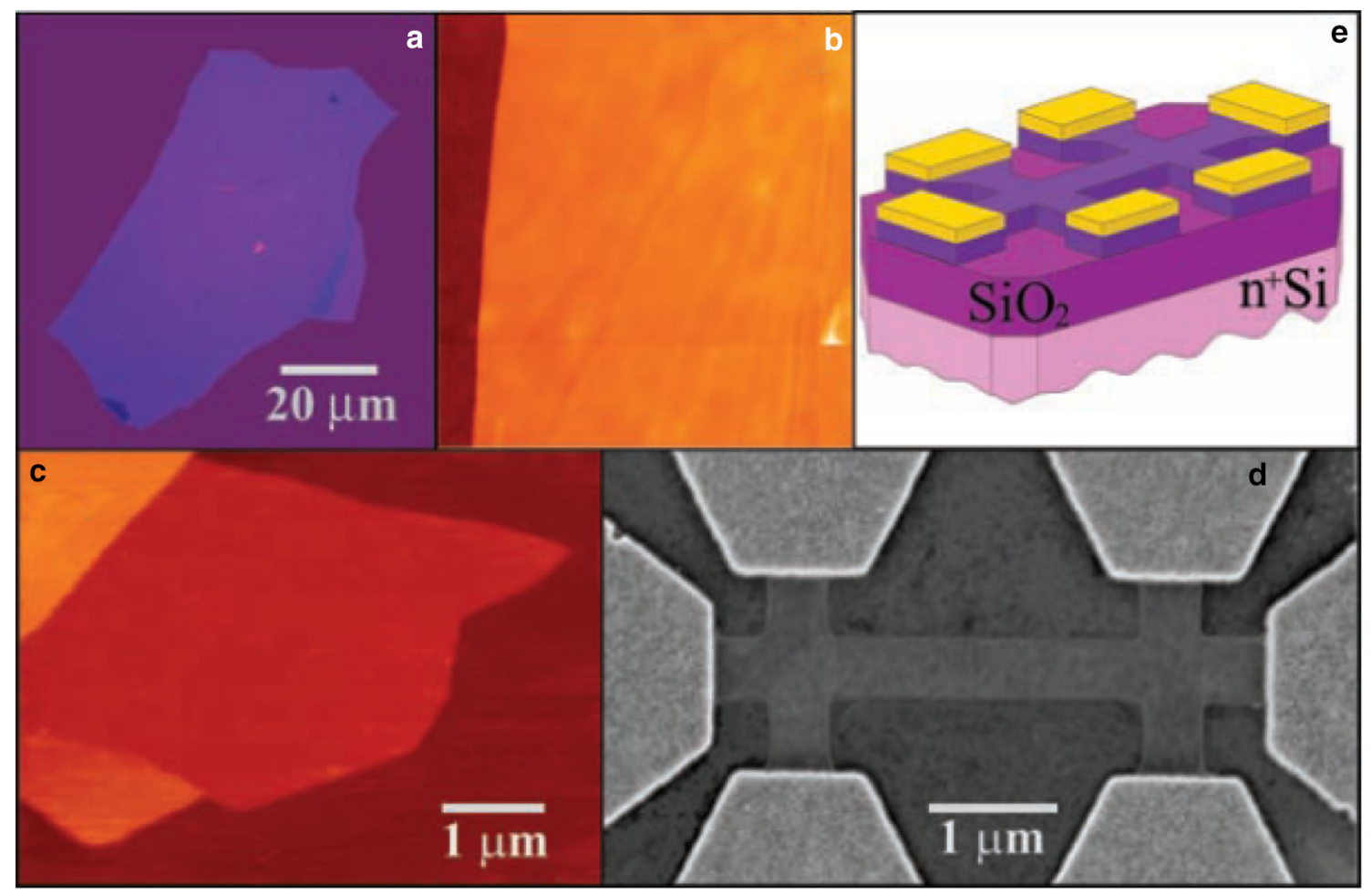

Fig. 3 Graphene films. a Photograph (in normal white light) of a relatively large multilayer graphene flake with thickness $\sim 3 \mathrm{~nm}$ on top of an oxidized Si wafer. b Atomic force microscope (AFM) image of $2 \mu \mathrm{m}$ by $2 \mu \mathrm{m}$ area of this flake near its edge. Colors: dark brown, $\mathrm{SiO}_{2}$ surface; orange, $3 \mathrm{~nm}$ height above the $\mathrm{SiO}_{2}$ surface. c AFM image of single-layer graphene. Colors: dark brown, $\mathrm{SiO}_{2}$ surface; brown-red (central area), $0.8 \mathrm{~nm}$ height; yellow-brown (bottom left), $1.2 \mathrm{~nm}$; orange (top left), $2.5 \mathrm{~nm}$. d Scanning electron microscope image of FLG (Few layer graphene). e Schematic view of the device in (D) with permission of [15] 
FET devices (Fig. 3). Still, the mechanical exfoliation method needs to be enhanced further for large-scale, defect-free, high-purity graphene for mass production in the field of nanotechnology.

\section{Chemical exfoliation}

Chemical method is one of the best appropriate method for synthesis of graphene. In chemical method producing colloidal suspension which modify graphene from graphite and graphite intercalation compound. Different types of paper like material [20], [76-80] polymer composites [18], energy storage materials [81] and transparent conductive electrodes [82] have already used chemical method for production of graphene. In 1860 graphene oxide was first manufactured Brodie [83], Hummers [84] and Staudenmaier [85] methods. Chemical exfoliation is a two-step process. At first reduces the interlayer van der Waals forces to increase the interlayer spacing. Thus it forms grapheneintercalated compounds (GICs) [86]. Then it exfoliates graphene with single to few layers by rapid heating or sonication. For single-layer graphene oxide (SGO) uses ultrasonication [84, 87-91] and various layer thickness using Density Gradient Ultracentrifugation [92, 93]. Graphene oxide (GO) is readily prepared by the Hummers method involving the oxidation of graphite with strong oxidizing agents such as $\mathrm{KMnO}_{4}$ and $\mathrm{NaNO}_{3}$ inH$_{2} \mathrm{SO}_{4} /$ $\mathrm{H}_{3} \mathrm{PO}_{4}$ [84, 94]. Ultrasonication in a DMF/water $(9: 1)$ (dimethyl formamide) mixture used and produced single layer graphene. For this reason interlayer spacing increases from 3.7 to $9.5 \AA$. For oxidization high density of functional groups, and reduction needs to be carried out to obtain graphene-like properties. Single layer graphene sheets are dispersed by chemical reduction with hydrazine monohydrate $[88,90]$. Polycyclic aromatic hydrocarbons (PAHs) [94-96], has used for synthesis of graphene. Using a dendrict precursor transformed by cyclodehydrogenation and planarization [97].produce small domains of graphene. Poly-dispersed hyper branched polyphenylene, precursor give larger flakes [97]. The first were synthesized through oxidative cyclodehydrogenation with $\mathrm{FeCl}_{3}$ [97]. Variety of solvents are used to disperse graphene in perfluorinated aromatic solvents [54], orthodichloro benzene [98], and even in low-boiling solvents such as chloroform and isopropanol [99, 100]. Electrostatic force of attraction between HOPG and the $\mathrm{Si}$ substrate use in graphene on $\mathrm{SiO}_{2} / \mathrm{Si}$ substrates [65]. Laser exfoliation of HOPG has also been used to prepare FG, using a pulsed neodymium-doped yttrium aluminum garnet (Nd:YAG) laser [42, 101]. Thermal exfoliation and reduction of graphite oxide also produce good-quality graphene, generally referred to as reduced graphene oxide (RGO).

\section{Reduction graphene oxide}

Chemical reduction of graphite oxide is one of the conventional procedures to prepare graphene in large quantities [84]. Graphite oxide (GO) is usually synthesized through the oxidation of graphite using oxidants including concentrated sulfuric acid, nitric acid and potassium permanganate based on Brodie method [83], Staudenmaier method [85], Hummers method [84]. Another approach to the production of graphene is sonication and reduction of graphene oxide (GO). Addition of $\mathrm{H}_{2}$ occurs across the alkenes, coupled with the extrusion of nitrogen gas, large excess of $\mathrm{NaBH}_{4}$ have been used as a reducing agent [102]. Other reducing agents used include phenyl hydrazine [103], hydroxylamine [104], glucose, [105] ascorbic acid [106], hydroquinone [107], alkaline solutions [108], and pyrrole [109]. GO was formed by the chemical reaction between organic isocyanates and the hydroxyl is shown in Fig. 4 also mention the FT-IR spectra of GO.

Electrochemical reduction is another means to synthesize graphene in large scale [111-113]. In 1962, first established monolayer flakes of reduced graphene oxide. The graphite oxide solution can then be sonicated in order to form GO nanoplatelets. The oxygen groups can then be removed by using a hydrazine reducing agent, but the reduction process was found to be incomplete, leaving some oxygen remaining. GO is useful because its individual layers are hydrophilic, in contrast to graphite. GO is suspended in water by sonication $[114,115]$ then deposited on to surfaces by spin coating or filtration to make singleor double-layer graphene oxide. Graphene films are then made by reducing the graphene oxide either thermally or chemically [87] a simple one-step, solvo thermal reduction method to produce reduced graphene oxide dispersion in organic solvent [116]. The colloidal suspensions of chemically modified graphene (CMG) ornamented with small organic molecules [117]. Graphene functionalization with poly ( $m$-phenylenevinylene-co-2, 5-dioctoxy- $p$-phenylenevinylene) (PmPV) [118], 1,2-distearoyl-sn-glycero-3phosphoethanolamine- $N$ [methoxy (polyethyleneglycol)5000] (DSPE-mPEG) [119], poly (tert-butyl acrylate). Here two cross-sectional FE-SEM and TEM pictures are shown in Fig. 5 for distinguishing GO and RGO.

\section{Pyrolysis of graphene}

Solvo thermal method was used as a chemical synthesis of graphene in bottom up process. In this thermal reaction the molar ratio of sodium and ethanol was 1:1 in closed vessel. Graphene sheets could be smoothly detached by pyrolization of sodium ethoxide using sonication. This produced 


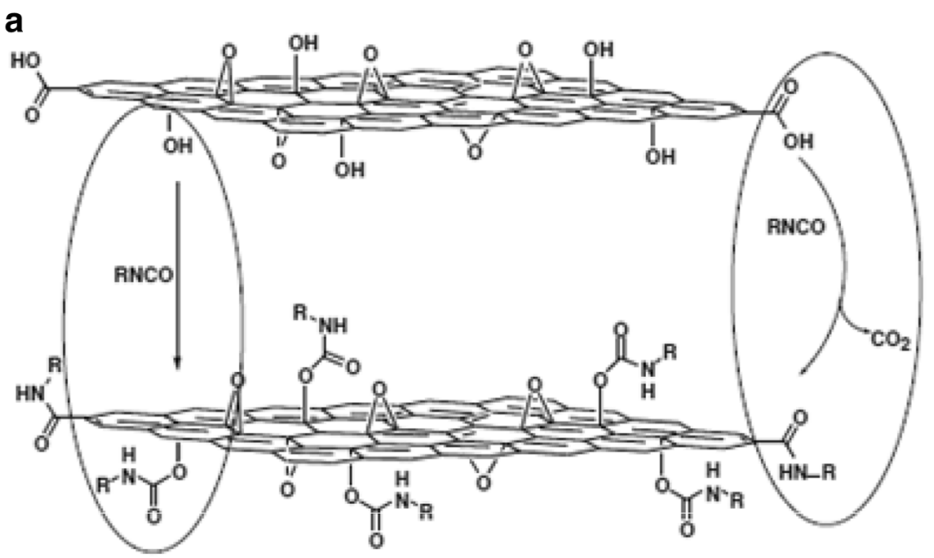

b

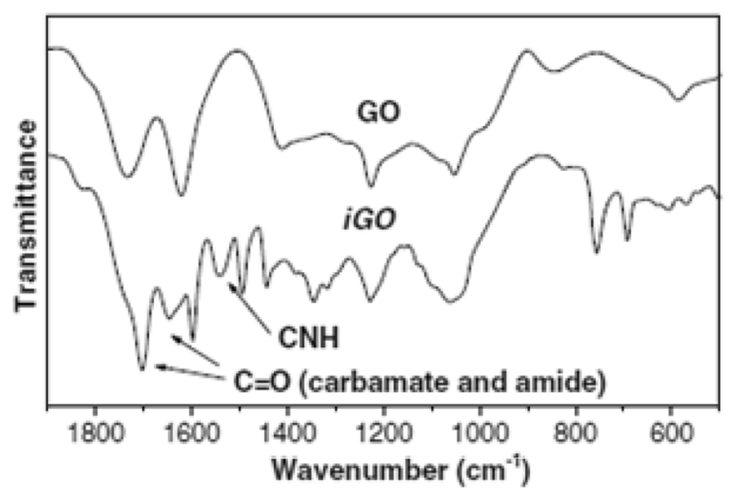

Fig. 4 a Proposed reactions during the isocyanate treatment of GO where organic isocyanates react with the hydroxyl (left oval) of graphene oxide sheets to form carbamate and amide functionalities,

respectively. b FT-IR spectra of GO and isocyanate-treated GO. With permission of [110]

Fig. 5 Cross-sectional FE-SEM images of (a) graphene oxide (GO) (b) Reduced graphene oxide (RGO) with permission of [120]. Cross-sectional TEM images of (c) graphene oxide (GO) [121] (b) Reduced graphene oxide (RGO) with permission of [122]
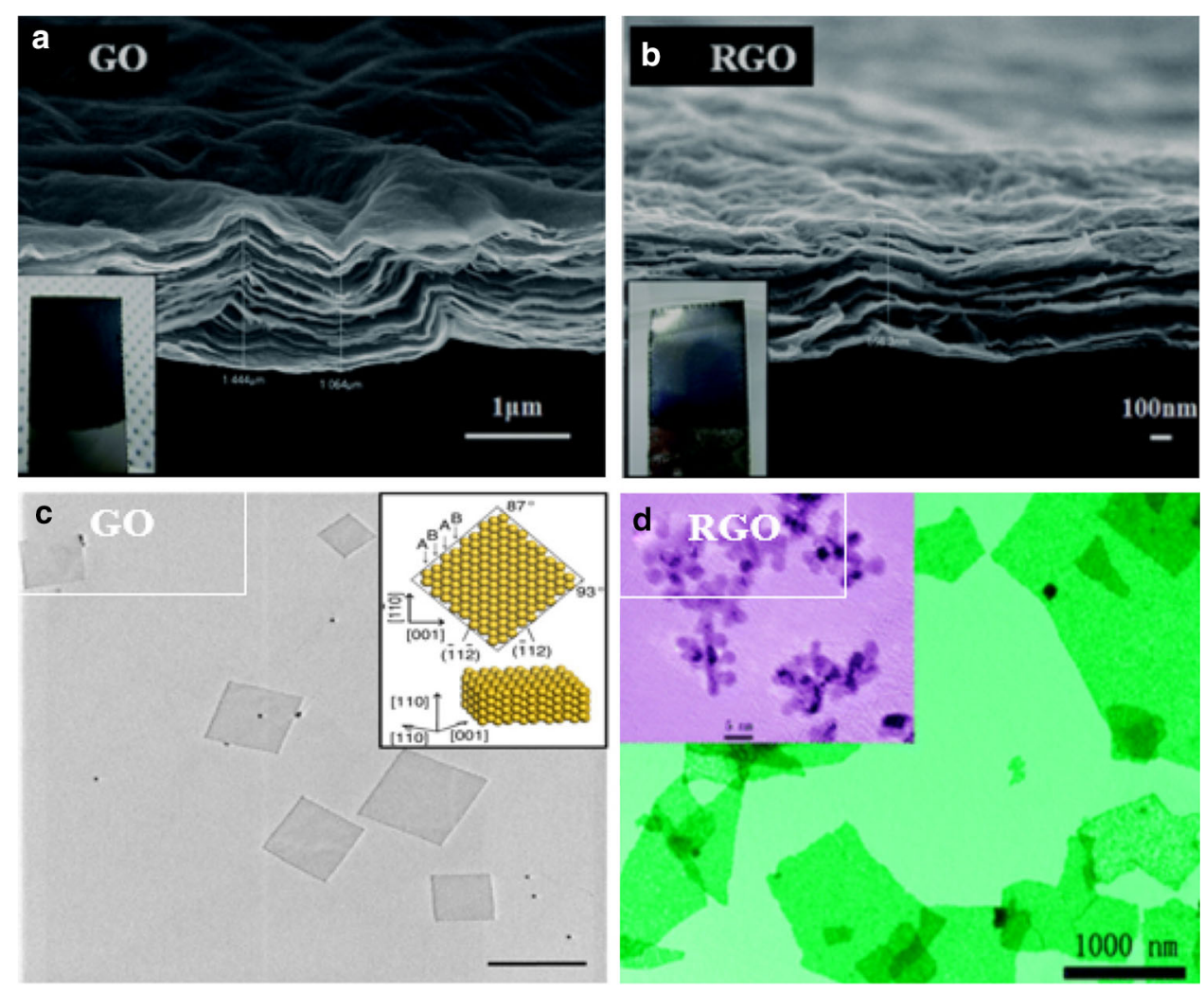

graphene sheets with dimensions of up to $10 \mu \mathrm{m}$. The crystalline structure, different layers, graphitic nature, band structure were inveterate by SAED, TEM and Raman spectroscopy [123]. Raman spectroscopy of the resultant sheet showed a broad D-band, G-band, and the intensity ratio of IG/ID $\sim 1.16$, representative of defective graphene. The benefits of this process were low-cost and easily fabricated of high-purity, functionalized graphene in low temperature. Yet, the quality of graphene was still not suitable because it comprised a large number of defects.

\section{Chemical vapor deposition (CVD)}

Chemical vapor deposition comprises chemical reaction on which process molecules are heated and changed to a gaseous state and that is called precursor. In this CVD process a substrate is diffused on thermally disintegrated precursors in high temperature. It deposits on thin films, crystalline, solid, liquid or gaseous precursors on the surface of the substrate. The deposition of high-quality graphene from CVD process is usually done onto various transition-metal substrates like 
Table 3 Concise illustration of CVD synthesis and characteristics

\begin{tabular}{|c|c|c|c|c|c|}
\hline Cvd synthesis characteristics & $\begin{array}{l}\text { Hydrocarbon and other } \\
\text { chemical ratio }\end{array}$ & Temperature & Pressure & Special characteristics & References \\
\hline Thin layer graphite on $\mathrm{Ni}$ & $\mathrm{H}_{2}: \mathrm{CH}_{4} \equiv 92: 8$ & $950{ }^{\circ} \mathrm{C}$ & $40-80 \mathrm{mT}$ & $\begin{array}{l}1-2 \mathrm{~nm} \text { layer } \\
\text { DC discharge of the current } \\
\quad \sim 0.5 \mathrm{~A} / \mathrm{cm}^{2}\end{array}$ & [129] \\
\hline $\begin{array}{l}\text { Graphene formation on polycrystalline } \\
\mathrm{Ni}\end{array}$ & $\mathrm{CH}_{4}: \mathrm{H}_{2}: \mathrm{Ar} \equiv 0.15: 1: 2$ & $1000^{\circ} \mathrm{C}$ & $1 \mathrm{~atm}$ & 3-4 layer & {$[128]$} \\
\hline $\begin{array}{l}\text { Graphene growth over e-beam } \\
\text { evaporated } \mathrm{Ni}\end{array}$ & $\begin{array}{l}\mathrm{CH}_{4}: \mathrm{H}_{2}: \mathrm{Ar} \\
\quad \equiv 550: 65: 200\end{array}$ & $1000^{\circ} \mathrm{C}$ & - & $\begin{array}{l}\text { Large-scale monolayer } \\
\text { Sheet resistance } \sim 280 \\
\text { ohm/sq } \\
\text { Transmittance } 80 \%\end{array}$ & [124] \\
\hline $\begin{array}{l}\text { Graphene formation on polycrystalline } \\
\mathrm{Ni} \text { by wet-etching }\end{array}$ & $\begin{array}{l}\text { Flow rate } \mathrm{Ar} \text { and } \mathrm{H}_{2} \\
10-20 \mathrm{~min}\end{array}$ & $900-1000{ }^{\circ} \mathrm{C}$ & - & & {$[31]$} \\
\hline $\begin{array}{l}\text { Gram-scale graphene using } \mathrm{MgO} \\
\text { catalyst }\end{array}$ & $\begin{array}{l}\mathrm{CH}_{4}: \mathrm{Ar} \equiv 1: 4 \text { Flow rate } \\
\quad 3751 / \mathrm{min}\end{array}$ & $1000^{\circ} \mathrm{C}$ & $40 \mathrm{~m}$ Torr & $\begin{array}{l}\text { 5-layer graphene sheet } \\
\text { Substrate free }\end{array}$ & {$[38]$} \\
\hline Catalytic graphene deposition on $\mathrm{Cu}$ & $\begin{array}{l}2 \mathrm{sccm} \text { flow rate } \\
35 \mathrm{sccm} \text { flow rate }\end{array}$ & $\begin{array}{l}1000^{\circ} \mathrm{C} \\
1000^{\circ} \mathrm{C}\end{array}$ & $\begin{array}{l}40 \mathrm{~m} \text { Torr } \\
500 \mathrm{~m} \text { Torr }\end{array}$ & $\begin{array}{l}\text { Single, double and triple } \\
\text { layer graphene }\end{array}$ & {$[17]$} \\
\hline $\begin{array}{l}\text { Graphene growth using } \\
15 \mathrm{~cm} \times 5 \mathrm{~cm} \\
\text { Rectangular } \mathrm{Cu} \text { foil }\end{array}$ & $\mathrm{H}_{2}: \mathrm{CH}_{4} \equiv 1: 4$ & $1000^{\circ} \mathrm{C}$ & - & - & {$[138]$} \\
\hline \multirow[t]{3}{*}{$\begin{array}{l}\text { Roll-to-roll production of graphene on } \\
\text { a flexible polymer }\end{array}$} & $\begin{array}{l}\text { Annealing of } \mathrm{Cu} \text { in } \mathrm{a}_{2} \\
\text { environment }\end{array}$ & $1000^{\circ} \mathrm{C}$ & $90 \mathrm{mT}$ & - & [139] \\
\hline & $\begin{array}{l}\text { Using precursor } \mathrm{CH}_{4} \text { and } \\
\mathrm{H}_{2}(3: 1)\end{array}$ & $1000^{\circ} \mathrm{C}$ & $460 \mathrm{mT}$ & & \\
\hline & cooling of the furnace & $\begin{array}{l}10^{\circ} \mathrm{C} / \mathrm{min} \text { under } \\
\mathrm{H}_{2} \text { flow }\end{array}$ & $90 \mathrm{mT}$ & & \\
\hline
\end{tabular}

as Ni [124] Pd [123], $\mathrm{Ru}$ [49], Ir [126], and $\mathrm{Cu}$ [31]. CVD growth of graphene has been mainly practiced on copper [31, 127] and nickel [31, 124, 128] substrates. Nickel was the first substrate on which CVD growth of large area graphene was attempted. These efforts had begun right from 2008. [129].In 1966 [130] Ni exposed to methane at $T=900{ }^{\circ} \mathrm{C}$ to form thin graphite, to be used as sample support for electron microscopy. In 1971, they [131] observed the formation of FLGs via evaporation of C from a graphite rod [131]. Deposition of mono-layer graphitic materials on Pt by thermal CVD was first reported in 1975 [26]. Later, Eizenberg and Blakely [24] reported graphite layer formation on $\mathrm{Ni}$ (111). In 1984 researcher [132] performed what may be the first CVD graphene growth on a metal surface, Ir, to study the catalytic and thermionic properties of Ir in the presence of carbon [133]. The physical and chemical properties of graphene have been precisely analyzed to open a new area of graphene-based electronics [15, 134-136]. In 2006, the first attempt at graphene synthesis on $\mathrm{Ni}$ foil using CVD was done using camphor (terpinoid, a white transparent solid of chemical formula $\mathrm{C}_{10} \mathrm{H}_{16} \mathrm{O}$ ) as the precursor material [137]. Different hydrocarbons such as methane, ethylene, acetylene, and benzene were decomposed on various transitionmetal substrates such as $\mathrm{Ni}, \mathrm{Cu}, \mathrm{Co}, \mathrm{Au}$, and $\mathrm{Ru}$ [31]. Single crystals using an ethylene precursor was found to yield graphene structurally coherent even over the Ir step edges [126]. Using methane as a hydrocarbon Table 3 can emblem a summary of significant researcher's contribution.

\section{Classification of CVD process}

Depending on the material quality, precursors, the width, and the structure required; there are many various types of CVD processes: thermal, plasma enhanced (PECVD), cold wall, hot wall, reactive, and so on.

In CVD process reactors like hot wall reactor, there temperature is relatively constant everywhere and these walls never get heated in cold wall system. Graphene is formed on $\mathrm{Cu}$ thin film mostly by cold wall system.

\section{Growth on $\mathrm{Cu}$}

Graphene growth on copper shows that it may emerge as alternate route towards scalable growth of graphene with higher monolayer coverage [17, 140]. In 2009, the first CVD growth of uniform as well as large area $\left(\sim \mathrm{cm}^{2}\right)$ graphene on a metal surface was done on polycrystalline $\mathrm{Cu}$ foils by exploiting thermal catalytic decomposition of methane [17]. 
Copper foil was an even superior substrate for growing single layer graphene films [17]. Although copper is an inexpensive substitute in contrast to other metals that is also simply extractable by etchants without chemically affecting graphene. For a very small solubility of carbon in copper, the carbon deposition process was found to be largely self-limiting [17]. The solubility of carbon in copper is negligible of the perspective of ppm even at $1000{ }^{\circ} \mathrm{C}$ [141] so the carbon precursor forms graphene directly on copper surface through growth step [17]. Cu surface is fully enclosed with graphene, save around $5 \%$ of the comprising of BLG and 3LG [17, 142] area (Fig. 6). Surface roughness is known to produce graphene thickness variation on copper [143, 144]. Since graphene growth on copper is surface limited, so smoothness

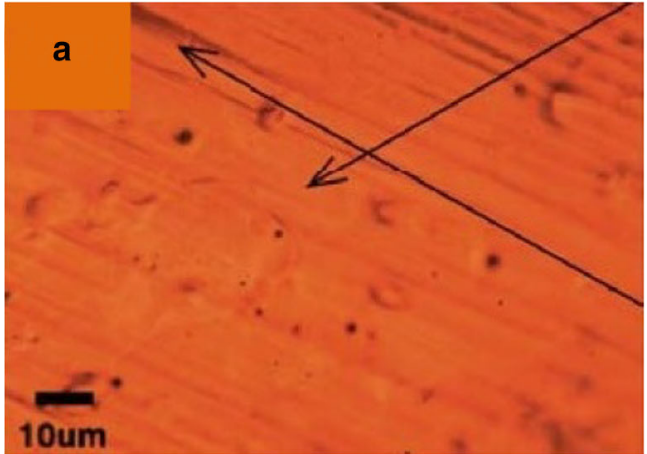

Fig. 6 a Optical image of as grown graphene on copper, the corrugations on metal foil are indicated by black arrows. b Same graphene when shifted to $300 \mathrm{~nm} \mathrm{SiO}_{2}$. Here dark purple areas highlighted by black arrows displays that even on low carbon solubility metal like copper, corrugations on starting substrate can result in formation of significant multilayer regions along with monolayer graphene [45]. Li et al. used CVD process to produce large-scale monolayer graphene on copper foils. $25 \mu \mathrm{m}$ thick copper

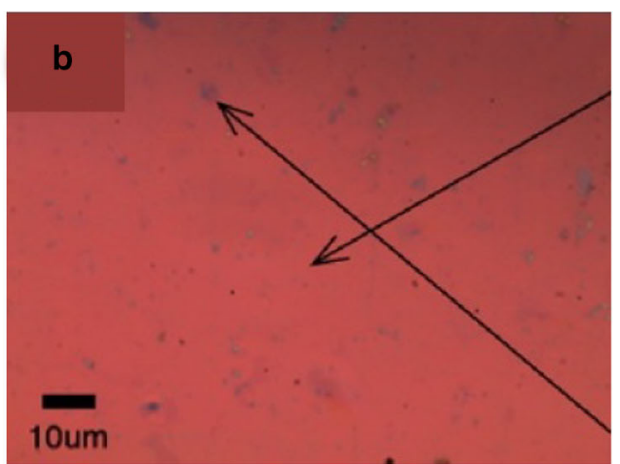

foils were first heated to $1000 \mathrm{C}$ in a flow of $2 \mathrm{sccm}$ (standard cubic centimeters per minute) hydrogen at low pressure and then exposed to methane flow of $35 \mathrm{sccm}$ and pressure of $500 \mathrm{mT}$ Torr and acquired sheet resistances of $125 \Omega / \mathrm{W}$ for a single layer. Using a repeated transfer method, doped 4-layer graphene sheets were formed with sheet resistances as low as $30 \Omega / \mathrm{W}$ and optical transmittance greater than $90 \%$. These 4-layer graphene sheets are better to commercially accessible indium tin oxide (ITO). Permission from [146]

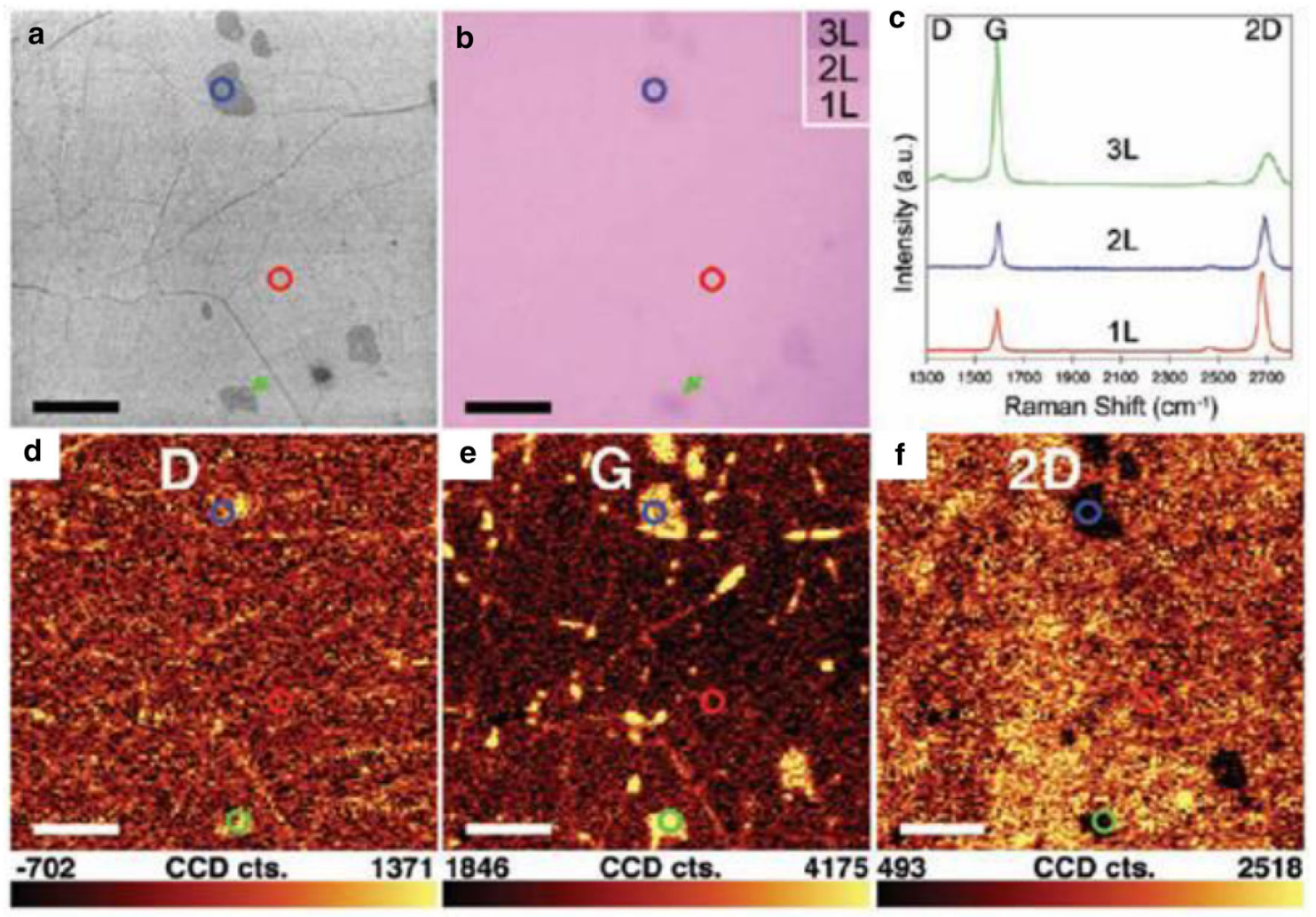

Fig. 7 Raman spectroscopy and SEM imaging of single layer graphene grown on copper (With Permission) [17] 
of copper surface imparts very significant role in receiving monolayer coverage across the whole surface of the substrate [145].

Again $\mathrm{Li}$ et al. have shown at $1035^{\circ} \mathrm{C}$ with methane flow of $7 \mathrm{sccm}$ and pressure $160 \mathrm{~m}$ Torr led to the largest graphene domains with average areas of $142 \mu \mathrm{m}^{2}$. Using this technique, they were able to produce samples with carrier mobility of up to $16,000 \mathrm{~cm}^{2} \mathrm{~V}^{-1} \mathrm{~s}^{-1}$ [147]. Usually, the graphene layer is slightly strained on the copper foil because of the high-temperature growth [148] (Fig. 7). Formation of graphene on Cu by LPCVD was then scaled up in 2010 where, growing the $\mathrm{Cu}$ foil size (30 inches), generating films with $\mu \sim 7350 \mathrm{~cm}^{2} \mathrm{~V}^{-1} \mathrm{~s}^{-1}$ at $6 \mathrm{~K}$. Large grain, $\sim 20-500 \mu \mathrm{m}$, graphene on $\mathrm{Cu}$ with $\mu$ ranging from $\sim 16,400$ to $\sim 25,000 \mathrm{~cm}^{2} \mathrm{~V}^{-1} \mathrm{~s}^{-1}$ at RT after transfer to $\mathrm{SiO}_{2}$ was reported in references [147, 149] and from $\sim 27,000$ to $\sim 45,000 \mathrm{~cm}^{2} \mathrm{~V}^{-1} \mathrm{~s}^{-1}$ on h-BN at RT [149]. Graphene was also formed on $\mathrm{Cu}$ by exposing it to liquids or solid hydrocarbons $[150,151]$ reported growth using benzene in the $\mathrm{T}$ range $300-500{ }^{\circ} \mathrm{C}$. However based on recent studies on CVD growth on copper have demonstrated copper to be a more auspicious substrate [17].

\section{Growth on Ni}

Due to few disturbing properties of $\mathrm{Cu}$ like surface roughening and sublimation; the researcher had to search for new substrates that was $\mathrm{Ni}$ substituting the $\mathrm{Cu}$. Graphene was synthesized by $\mathrm{Ni}$ foil, polycrystalline nickel thin film, patterned Ni thin film [152].

The foils were first annealed in hydrogen and then bare to a $\mathrm{CH}_{4}-\mathrm{Ar}-\mathrm{H}_{2}$ environment at atmospheric pressure for $20 \mathrm{~min}$ at a temperature of $1000{ }^{\circ} \mathrm{C}$ [128].The thickness of the graphene layers was found to be reliant on the cooling rate, with few layer graphene. Faster cooling rates consequence in thicker graphite layers, whereas slower cooling avoids carbon from separating to the surface of the Ni foil [128]. Still, the $\mathrm{T}$ range within which graphene can be grown on Ni is very thin, $100{ }^{\circ} \mathrm{C}$ [153], and could end in a Ni 2C phase [153], which can give rise to defects within the $\mathrm{Ni}$ crystal. In a nutshell any graphene grown on the surface could be non-uniform through the $\mathrm{Ni}-\mathrm{Ni} 2 \mathrm{C}$ regions (Fig. 8). The problems of $\mathrm{Ni}$ synthesis were time-consuming exposure to the carbon precursor, not self-limiting, catalyzed growth with large number of wrinkles and folds.

\section{Plasma-enhanced chemical vapor deposition}

Plasma-enhanced chemical vapor deposition (PECVD) generates plasma in void chamber which deposits thin flim on the substrate surface. It comprises with chemical
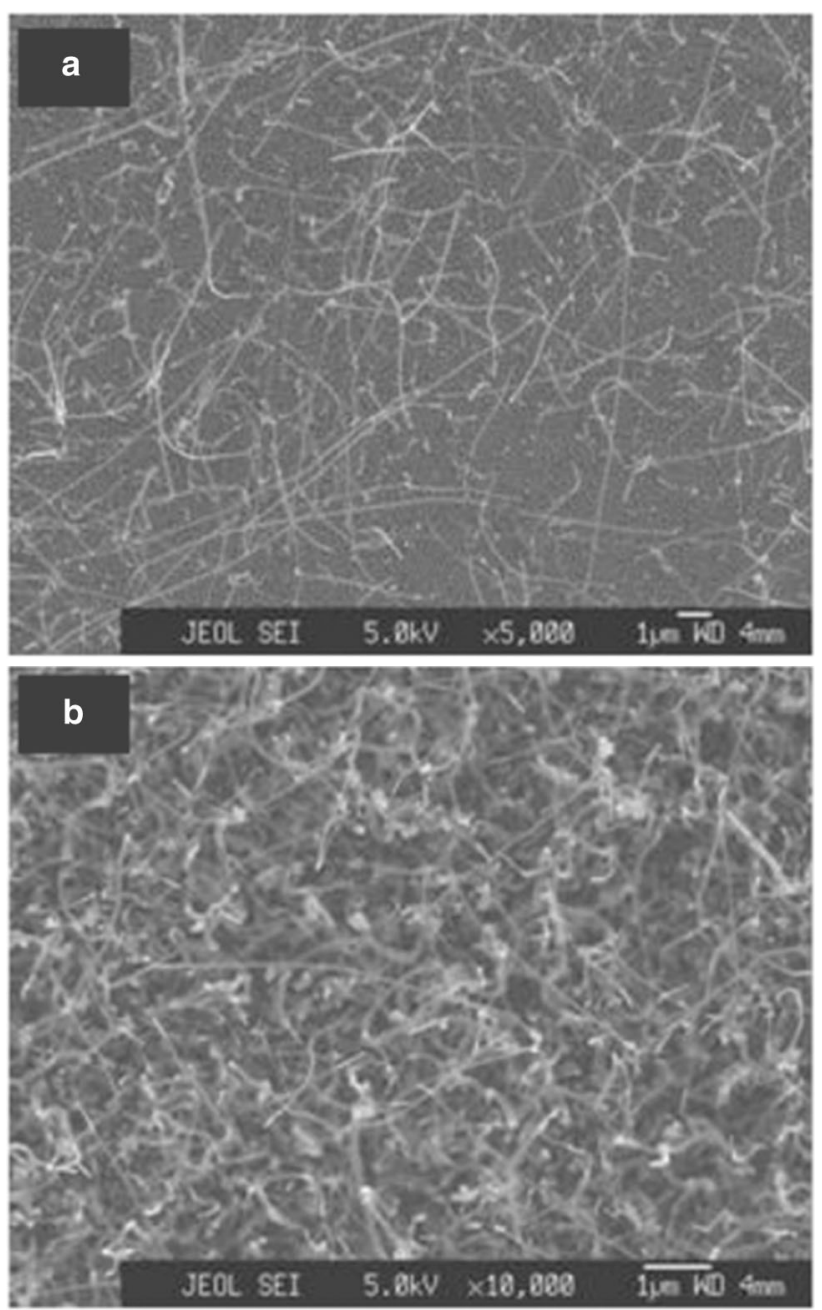

Fig. 8 SEM images of sample by CVD growth method on Ni film at $900-1000{ }^{\circ} \mathrm{C}$ at various $\mathrm{H}_{2}: \mathrm{CH}_{4}$ ratios with permission of [154]

reaction of the reacting gases.IN PECVD system uses RF (AC frequency), microwave, and inductive coupling (electrical currents produced by electromagnetic induction). It can be done at relatively low temperature, more feasible for large-scale industrial application and also catalyst free graphene fabrication [155]. Though it is costly and gas-phase precursor materials are used. The first synthesis of graphene sheets was established [156]. The production of mono- and few layer of graphene by PECVD on different substrates like $\mathrm{Si}, \mathrm{SiO}_{2}, \mathrm{Al}_{2} \mathrm{O}_{3}, \mathrm{Mo}, \mathrm{Zr}$, Ti, Hf, $\mathrm{Nb}, \mathrm{W}, \mathrm{Ta}, \mathrm{Cu}$, and 304 stainless steel. Using 900-watt RF power, $10 \mathrm{sccm}$ total gas flow, and inside chamber pressure of $\sim 12 \mathrm{~Pa}$, gas mixture 5-100 \% $\mathrm{CH}_{4}$ in $\mathrm{H}_{2}$ and 600-900 substrate temperature [157]. The plasma was deposited within 5-40 min. For complementary metal-oxide semiconductor (CMOS) devices it is need to reduce the temperature. PECVD reduces temperature during deposition was widely exploited in the growth of nanotubes and amorphous carbon [158-163]. When at $T=317^{\circ} \mathrm{C}$ to 
make TCs with Rs $\sim 2 \mathrm{k} \Omega /$ at $78 \%$ transmittance. Inductively coupled plasma (ICP) CVD, was used to grow graphene on $150 \mathrm{~mm} \mathrm{Si}$ wafers [164], reaching uniform films and good transport properties (i.e., $\mu$ up to $\sim 9000 \mathrm{~cm}^{2}$ $\left.\mathrm{V}^{-1} \mathrm{~s}^{-1}\right)$.

\section{Epitaxial growth of graphene}

Epitaxial thermal growth on a single crystalline silicon carbide $(\mathrm{SiC})$ surface is one of the most praised methods of graphene synthesis. The term "epitaxy" derives from the Greek, the prefix epi means "over" or "upon" and taxis means "order" or "arrangement". When the deposition of a single crystalline film on a single crystalline substrate produces epitaxial film and the process is known as epitaxial growth. It fabricates high-crystalline graphene onto single-crystalline $\mathrm{SiC}$ substrates. There are two general epitaxial growth processes depending on the substrate, homo-epitaxial and hetero-epitaxial growth. When the film deposited on a substrate is of the same material it is known as a homo-epitaxial layer, and if the film and substrate are different materials it is called a hetero-epitaxial layer. Sic first used as on electrical measurements on patterned epitaxial graphene on electrical measurements on patterned epitaxial graphene. In 2004 [16] $\mathrm{SiC}$ is a wide band gap semiconductor $(3 \mathrm{eV})$ and thus electrical measurements can be carried out using it as the substrate. In 1975, Bommel et al. [165] first reported graphite formation on both the $6 \mathrm{H}-\mathrm{SiC}(0001)$ surfaces. The heat treatment in the range of $1000-1500{ }^{\circ} \mathrm{C}$ in an ultrahigh vacuum $(\sim 10-10 \mathrm{~m}$ bar $)$ manufactured graphite on both of the $\mathrm{SiC}$ polar planes (0001). In 2004, de Heer's [166] group reported the fabrication of ultrathin graphite consisting of 1-3 monoatomic graphene layers on the $\mathrm{Si}$ completed (0001) face of single-crystal $6 \mathrm{H}-\mathrm{SiC}$ and explored its electronic properties [167]. The growth rate of graphene on $\mathrm{SiC}$ depends on the specific polar SiC crystal face [166, 167]. Graphene forms much faster on the C- than on the Si-face $[166,167]$. On the C-face, larger domains $(\sim 200 \mathrm{~nm})$ of multilayered, rotationally disordered graphene are produced [167, 168]. On the Si-face, UHV annealing leads to small domains, 30-100 nm [168, 169]. (Si (0001)- and C (000-1)-terminated) annealed at high $T\left(>1000{ }^{\circ} \mathrm{C}\right)$ under ultra-high vacuum (UHV) graphitize due to the evaporation of $\mathrm{Si}[170,171]$. Graphene films by thermal decomposition of $\mathrm{SiC}$ above $1000{ }^{\circ} \mathrm{C}$, graphene grows on a C-rich $6 \sqrt{ } 3 \times 6 \sqrt{ } 3 \mathrm{R} 30^{\circ}$ rebuilding with respect to the $\mathrm{SiC}$ surface $[172,181]$. Epitaxial graphene growth on $\mathrm{SiC}$ has been visualized as a very promising method for largescale production and commercialization of graphene for applications into electronics. Graphene on $\mathrm{SiC}$ produces high-frequency electronics [173], light emitting devices [173], and radiation hard devices [173]. Top gated transistors have been fabricated from graphene on $\mathrm{SiC}$ on a wafer scale [174]. High-frequency transistors have also been revealed with $100 \mathrm{GHz}$ cut-off frequency208 [175], higher than state of the art $\mathrm{Si}$ transistors of the same gate length [176]. Graphene on $\mathrm{SiC}$ has been established as a novel resistance standard based on the quantum Hall effect (QHE) [177]. Though this process is very expensive.

\section{Unzipping method}

Chemical and plasma-etched method uses in unzipping a carbon nanotube (CNT). Graphene nano ribbon (GNR) defines a thin elongated strip of graphene which demonstrates straight edges. Transformation of electronic state from semimetal to semiconductor depends on the width of nanaotube [178]. Multi-layer graphene or singlelayer graphene produces if the starting nanotube is multiwalled or single walled. The width of the nanoribbons thus produced depends on the diameter of the precursor nanotubes. Multi-walled carbon nanotubes (MWNTs) established by lithium (Li) and ammonia $\left(\mathrm{NH}_{3}\right)$. Conversion of graphene nanoribbon from (MWNTs) are shown in Fig. 9.

Liquid $\mathrm{NH}_{3}(99.95 \%)$ and dry tetrahydrofuran (THF) used in growth of (MWNTs) retaining the dry ice bath temperature of $-77^{\circ} \mathrm{C}$ [179]. It was found that $\sim 60 \%$ fully exfoliated and $(0-5 \%)$ unexfoliated or partially exfoliated nanotubes of (MWNTs). For Oxidation of CNT's side wall used $\mathrm{H}_{2} \mathrm{SO}_{4}, \mathrm{KMnO}_{4}$, and $\mathrm{H}_{2} \mathrm{O}_{2}$ in step by step process [32]. At the beginning they reported that the MWNT diameter was $40-80 \mathrm{~nm}$ and increased up to $100 \mathrm{~nm}$. The step-by-step fabrication process from nanotube to nanoribbon is shown in Fig. 10.

In controlled unzipping technique a pristine MWNT (dia. 4-18 nm) suspension was put on to a Si substrate pretreated with 3-aminopropyltriethoxysilane. A polymethylmethacrylate (PMMA) solution [34]. They established high quality of MWNTs which diameter were $\sim 6-12 \mathrm{~nm}$ and step height GNRs were $0.8-2.0 \mathrm{~nm}$. Again single- to few-layer GNRs also depends on the plasma etching time.

Another method for unzipping MWCNTs to GNRs used electric field. An electric field was applied to a single MWNT using a tungsten electrode and perceived that the noncontact end of the MWCNT started unwrapping and forming graphene nanoribbon. The fabrication process of GNRs achieve a high-purity, defect-free controlled synthesis process for scalable device in modern electronics. 

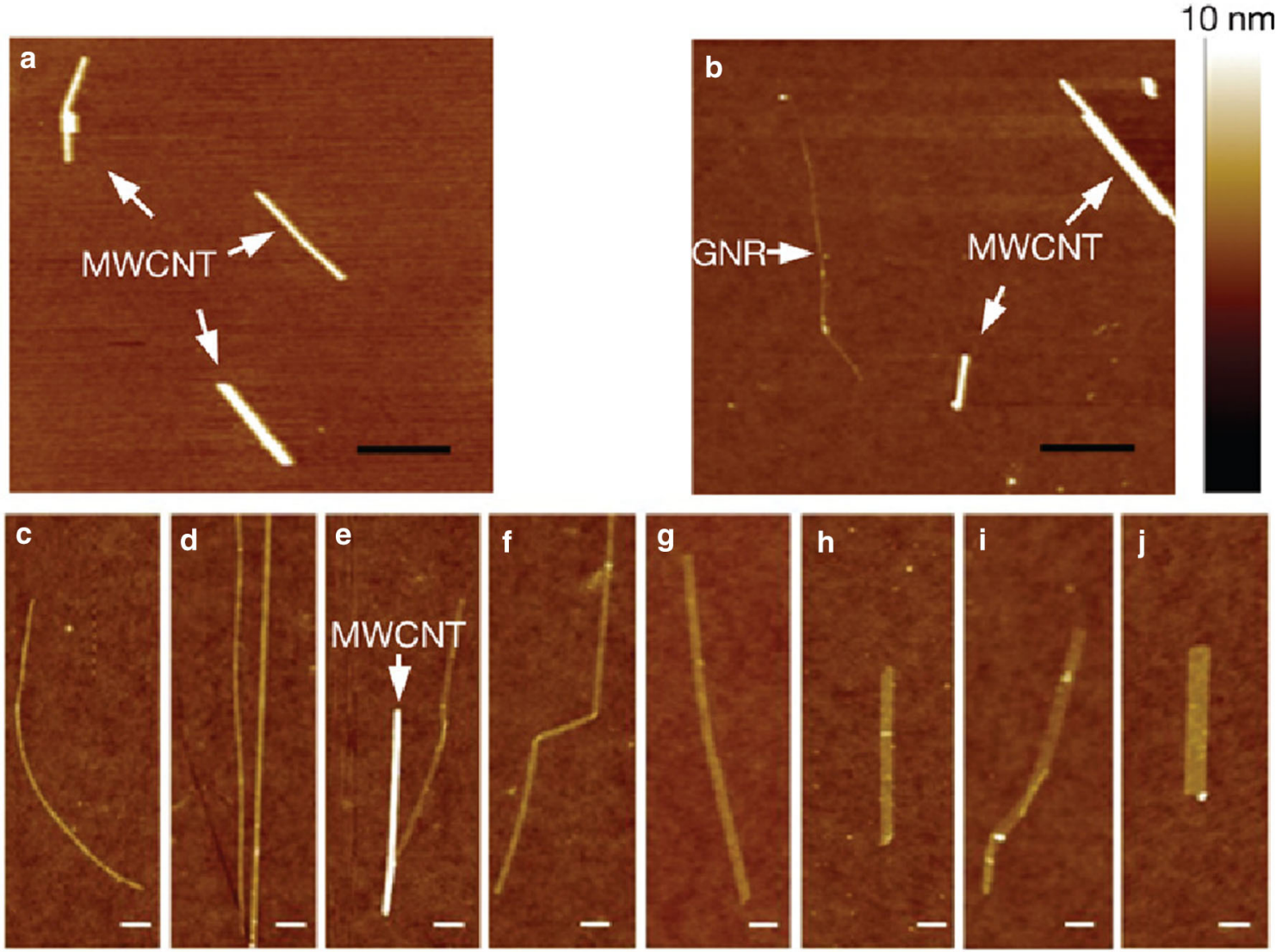

Fig. 9 The Images of graphene nanoribbons (GNRs) converted from Multi-wall carbon nanaotubes (MWCNTs) with permission of [34]

\section{Others method}

There are several other ways to produce graphene such as electron beam irradiation of PMMA nanofibres [180], arc discharge of graphite [181], thermal fusion of PAHs [182], and conversion of nano diamond [183]. Graphene can synthesis by arc discharge method in the presence of $\mathrm{H}_{2}$ atmosphere with two to three layers having flake size of 100-200 nm [180, 184]. By rapid heating process Arc discharge in an air atmosphere resulted in graphene nano sheets that are $\sim 100-200 \mathrm{~nm}$ wide predominantly with two layers [182]. The conditions that are favorable for obtaining graphene in the inner walls are high current (above $100 \mathrm{~A}$ ), high voltage $(>50 \mathrm{~V})$, and high pressure of hydrogen (above 200 Torr). The vintage of graphene layer depends strongly on the initial air pressure [185]. He and $\mathrm{NH}_{3}$ atmosphere are also used as arc discharge method [43]. In He atmosphere has considered gas pressure and currents to obtain different number of graphene sheets. In molecular beam deposition technique used ethylene gas source which deposited on a nickel substrate. Large-area, high-quality graphene layers were produced dependent on cooling rate.

\section{Applications}

In the field of application, the novel 2D material graphene plays a vanguard and outstanding role in this twenty-first century. The applications and applied areas of graphene are so vast that it is too many to describe here. The recent advances in the unique electronics, optical, magnetic, surface area, and mechanical properties of functionalized graphene have emerged new approach of green technology and innovative solution of existing problems like as electronic and photonic applications for ultrahigh-frequency graphene-based devices, nanosized graphene in material science, in ceramics, anode for li-ion battery, supercapacitor, lightweight natural gas tanks, sensors to diagnose diseases and solar cell [186]. In October 2014, international wheel producer Vittoria released a new range of bicycle race wheels built from graphene-enhanced composite materials. The new wheels (called Quarno) are the best wheels offered by Vittoria, and are said to be the fastest in the world [187]. In September 15th, 2015; the first flight of a UAV part-constructed with graphene have brought a new nano-material that the thinnest material on Earth [188]. Recently a group of researcher have developed a range of 


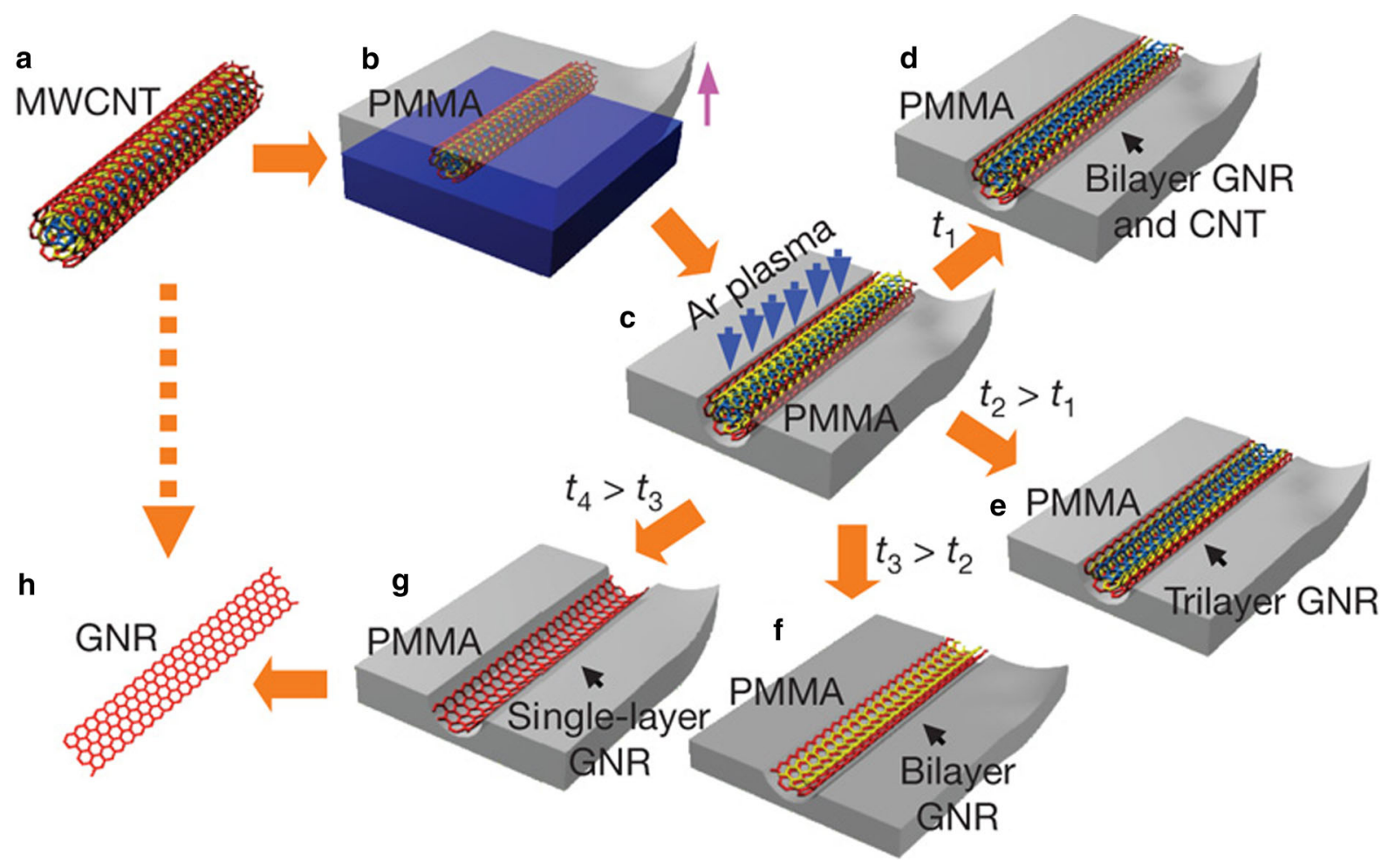

Fig. 10 A process flow chart of graphene nanoribbon fabrication from a carbon nanotube (CNT) by the plasma etching process with permission of [34]

membrane assemblies for advanced water treatment, including crumpled graphene oxide nanocomposites, which are highly water-permeable, photo reactive and antimicrobial. In future there will be myriad scope for disseminating this research concept [189].

\section{Conclusion}

Recently graphene the noble material has brought a revolutionary change in the field of nanoelectronics. Its outstanding contribution is not only limited in nanoelectronics but also expanding in medical science, nanorobotics, commercial manufacturing of graphene synthesized products and so on.

Acknowledgments We express deep sense of gratitude and indebtedness to our project supervisor Md. Nizam Uddin, Assistant Professor, Department of Mechanical Engineering for providing precious guidance, inspiring discussions and constant supervision throughout the course of this work. His help, constructive criticism, and conscientious efforts made it possible to present the work contained in this project. It's our goodness that in spite of having a tight and busy schedule supervisor has found time to help and guided us. For this, we again express our greatness to him. We are also grateful to those staff who help us directly or indirectly which was very essential to accelerate our work.
Open Access This article is distributed under the terms of the Creative Commons Attribution 4.0 International License (http://creative commons.org/licenses/by/4.0/), which permits unrestricted use, distribution, and reproduction in any medium, provided you give appropriate credit to the original author(s) and the source, provide a link to the Creative Commons license, and indicate if changes were made.

\section{References}

1. Bolotin, K.I., Sikes, K.J., Jiang, Z., Klima, M., Fudenberg, G., Hone, J., Kim, P., Stormer, H.L.: Ultrahigh electron mobility in suspended graphene. Solid State Commun. 146, 351-355 (2008). doi:10.1016/j.ssc.2008.02.024

2. Morozov, S.V., Novoselov, K.S., Katsnelson, M.I., Schedin, F., Elias, D.C., Jaszczak, J.A., Geim, A.K.: Giant intrinsic carrier mobilities in graphene and its bilayer. Phys. Rev. Lett. 100, 016602 (2008). doi:10.1103/PhysRevLett.100.016602

3. Lee, C., Wei, X.D., Kysar, J.W., Hone, J.: Measurement of the elastic properties and intrinsic strength of monolayer graphene. Science 321, 385-388 (2008). doi:10.1126/science.1157996

4. Balandin, A.A., Ghosh, S., Bao, W.Z., Calizo, I., Teweldebrhan, D., Miao, F., Lau, C.N.: Superior thermal conductivity of singlelayer graphene. Nano. Lett. 8(3), 902-907 (2008). doi:10.1021/ nl0731872

5. Moser, J., Barreiro, A., Bachtold, A.: Current-induced cleaning of graphene. Appl. Phys. Lett. 91, 163513 (2007). doi:10.1063/ 1.2789673

6. Cai, W., Zhu, Y., Li, X., Piner, R.D., Ruoff, R.S.: Large area few-layer graphene/graphite films as transparent thin conducting 
electrodes. Appl. Phys. Lett. 95, 123115 (2009). doi:10.1063/1. 3220807

7. Li, X., Zhu, Y., Cai, W., Borysiak, M., Han, B., Chen, D., Piner, R.D., Colombo, L., Ruoff, R.S.: Transfer of large-area graphene films for high-performance transparent conductive electrodes. Nano Lett. 9, 4359 (2009). doi:10.1021/n1902623y

8. Boehm, H.P., Clauss, A., Fischer, G.O., Hofmann, U.: The adsorption behavior of very thin carbon films. Z. Anorg. Allg. Chem. 316(3-4), 119-127 (1962). doi:10.1002/zaac. 19623160303

9. Boehm, H.P., Setton, R., Stumpp, E.: Nomenclature and terminology of graphite intercalation compounds (IUPAC Recommendations 1994). Pure Appl. Chem. 66(9), 1893-1901 (1994). doi:10.1351/pac199466091893

10. Boehm, H.P., Setton, R., Stumpp, E.: Nomenclature and terminology of graphite intercalation compounds. Carbon 24(2), 241-245 (1986). doi:10.1016/0008-6223(86)90126-0

11. Wintterlin, J., Bocquet, M.L.: Graphene on metal surfaces. Surf. Sci. 603(10-12), 1841-1852 (2009). doi:10.1016/j.susc.2008.08. 037

12. Vanbommel, A.J., Crombeen, J.E., Vantooren, A.: LEED and Auger electron observations of the $\mathrm{SiC}(0001)$ surface. Surf. Sci. 48(2), 463-472 (1975). doi:10.1016/0039-6028(75)90419-7

13. Lu, X.K., Yu, M.F., Huang, H., Ruoff, R.S.: Tailoring graphite with the goal of achieving single sheets. Nanotechnology 10(3), 269-272 (1999). doi:10.1088/0957-4484/10/3/308

14. Lu, X.K., Huang, H., Nemchuk, N., Ruoff, R.S.: Patterning of highly oriented pyrolytic graphite by oxygen plasma etching. Appl. Phys. Lett. 75, 193 (1999). doi:10.1063/1.124316

15. Novoselov, K.S., Geim, A.K., Morozov, S.V., Jiang, D., Zhang, Y., Dubonos, S.V., Grigorieva, I.V., Firsov, A.A.: Electric field effect in atomically thin carbon films. Science 306(5696), 666-669 (2004). doi:10.1126/science.1102896

16. Berger, C., Song, Z.M., Li, T.B., Li, X.B., Ogbazghi, A.Y., Feng, R., Dai, Z.T., Marchenkov, A.N., Conrad, E.H., First, P.N., De Heer, W.A.: Ultrathin epitaxial graphite: 2D electron gas properties and a route toward graphene-based nanoelectronics. J. Phys. Chem. B 108(52), 19912-19916 (2004). doi:10. 1021/jp040650f

17. Li, X.S., Cai, W.W., An, J.H., Kim, S., Nah, J., Yang, D.X., Piner, R., Velamakanni, A., Jung, I., Tutuc, E., Banerjee, S.K., Colombo, L., Ruoff, R.S.: Large-area synthesis of high-quality and uniform graphene films on copper foils. Science 324(5932), 1312-1314 (2009). doi:10.1126/science.1171245

18. Stankovich, S., Dikin, D.A., Dommett, G.H.B., Kohlhaas, K.M., Zimney, E.J., Stach, E.A., Piner, R.D., Nguyen, S.T., Ruoff, R.S.: Graphene-based composite materials. Nature 442, 282-286 (2006). doi:10.1038/nature04969

19. Watcharotone, S., Dikin, D.A., Stankovich, S., Piner, R., Jung, I., Dommett, G.H.B., Evmenenko, G., Wu, S.E., Chen, S.F., Liu, C.P., Nguyen, S.T., Ruoff, R.S.: Graphene-silica composite thin films as transparent conductors. Nano Lett. 7, 1888-1892 (2007). doi:10.1021/n1070477+

20. Dikin, D.A., Stankovich, S., Zimney, E.J., Piner, R.D., Dommett, G.H.B., Evmenenko, G., Nguyen, S.T., Ruoff, R.S.: Preparation and characterization of graphene oxide paper. Nature 448, 457-460 (2007). doi:10.138/nature06016

21. Park, S., Ruoff, R.S.: Chemical methods for the production of graphenes. Nat. Nanotechnol. 4, 217-224 (2009). doi:10.1038/ nnano. 2009.58

22. W. Choi, Jo-won Lee: Graphene: Synthesis and Applications, CRC Press, Taylor and Francis Group; Boca Raton London New York, Chapter-2, pp. 27-57

23. sA. Geim, K., Novoselov, K.S.: The rise of graphene. Nat. Mater. 6(3), 183-191 (2007). doi:10.1038/nmat1849
24. Eizenberg, M., Blakely, J.M.: Carbon monolayer phase condensation on Ni(111). Surf. Sci. 82(1-2), 228-236 (1979). doi:10.1016/0039-6028(79)90330-3

25. Eizenberg, M., Blakely, J.M.: Carbon interaction with nickel surfaces: monolayer formation and structural stability. J Chem Phys 71(8), 3467 (1979). doi:10.1063/1.438736

26. Lang, B.: A LEED study of the deposition of carbon on platinum crystal surfaces. Surface Science 53(1), 317-329 (1975). doi:10. 1016/0039-6028(75)90132-6

27. Zhang, Y.B., Small, J.P., Pontius, W.V., Kim, P.: Fabrication and electric-field dependent transport measurements of mesoscopic graphite devices. Appl. Phys. Lett. 86, 073104 (2005). doi:10.1063/1.1862334

28. Novoselov, K.S., Jiang, D., Schedin, F., Booth, T.J., Khotkevich, V.V., Morozov, S.V., Geim, A.K.: Two-dimensional atomic crystals. PNAS 102(3), 10451-10453 (2005). doi:10. 1073/pnas.0502848102

29. Allen, M.J., Tung, V.C., Kaner, R.B.: Honeycomb carbon: a review of graphene. Chem. Rev. 110(1), 132-145 (2010). doi:10.1021/cr900070d

30. Viculis, L.M., Mack, J.J., Kaner, R.B.: A chemical route to carbon nanoscrolls. Science 299(5611), 1361 (2003). doi:10. 1126/science. 1078842

31. Reina, A., Jia, X.T., Ho, J., Nezich, D., Son, H., Bulovic, V., Mildred Dresselhaus, S., Kong, J.: Large area, few-layer graphene films on arbitrary substrates by chemical vapor deposition. Nano Lett. 9(1), 30-35 (2009). doi:10.1021/nl801827v

32. Jiao, L.Y., Wang, X.R., Diankov, G., Wang, H.L., Dai, H.J.: Facile synthesis of high-quality graphene nanoribbons. Nat. Nanotechnol. 5(5), 321-325 (2010). doi:10.1038/nnano.2010.54

33. Kosynkin, D.V., Higginbotham, A.L., Sinitskii, A., Lomeda, J.R., Dimiev, A., Price, B.K., Tour, J.M.: Longitudinal unzipping of carbon nanotubes to form graphene nanoribbons. Nature 458(7240), 872-876 (2009). doi:10.1038/nature07872

34. Jiao, L.Y., Zhang, L., Wang, X.R., Diankov, G., Dai, H.J.: Narrow graphene nanoribbons from carbon nanotubes. Nature 458(7240), 877-880 (2009). doi:10.1038/nature07919

35. Xin, G. Q., W. Hwang, N. Kim, S. M. Cho, and H. Chae.: A graphene sheet exfoliated with microwave irradiation and interlinked by carbon nanotubes for high-performance transparent flexible electrodes. Nanotechnology Vol. 21, No. 40 (2010). 10.1088/0957-4484/21/40/405201

36. Sutter, P.: Epitaxial graphene: how silicon leaves the scene. Nat. Mater. 8(3), 171-172 (2009). doi:10.1038/nmat2392

37. Zhang, W., Cui, J., Tao, C.-A., Wu, Y., Li, Z., Ma, L., Wen, Y., Li, G.: A Strategy for producing pure single-layer graphene sheets based on a confined self-assembly approach. Angew. Chem. Int. Ed. 48(32), 5864-5868 (2009). doi:10.1002/anie. 200902365

38. Wang, X., You, H., Liu, F., Li, M., Wan, L., Li, S., Li, Q., Xu, Y., Tian, R., Yu, Z., Xiang, D., Cheng, J.: Large-scale synthesis of few-layered graphene using CVD. J. Chem. Vapor Deposition 15(1-3), 53-56 (2009). doi:10.1002/cvde.200806737

39. Wang, Y., Chen, X., Zhong, Y., Zhu, F., Loh, K.P.: Large area, continuous, few-layered graphene as anodes in organic photovoltaic devices. Appl. Phys. Lett. 95, 063302 (2009). doi:10. 1063/1.3204698

40. Dervishi, E., Li, Z., Watanabe, F., Biswas, A., Xu, Y., Alexandru, R.B., Saini, V., Alexandru, S.B.: Large-scale graphene production by RF-cCVD method. Chem. Commun. 27, 4061-4063 (2009). doi:10.1039/B906323D

41. Chong-an, D., Dacheng, W., Gui, Y., Yunqi, L., Yunlong, G., Daoben Z.: Patterned graphene as source/drain electrodes for bottom-contact organic field-effect transistors. Adv. Mater 20(17), 3289-3293 (2008). doi:10.1002/adma.200800150 
42. Chae, S.J., G€unes, F., Kim, K.K., Kim, E.S., Han, G.H., Kim, S.M., Shin, H.-J., Yoon, S.-M., Choi, J.-Y., Park, M.H., Yang, C.W., Pribat, D., Lee, Y.H.: Synthesis of large-area graphene layers on poly-nickel substrate by chemical vapor deposition: wrinkle formation. Adv. Mater 21(22), 2328-2333 (2009). doi:10.1002/adma.200803016

43. Li, N., Wang, Z., Zhao, K., Shi, Z., Gu, Z., Xu, S.: Large scale synthesis of $\mathrm{N}$-doped multi-layered graphene sheets by simple arc-discharge method. Carbon 48(1), 255-259 (2009). doi:10. 1016/j.carbon.2009.09.013

44. Karmakar, S., Kulkarni, N.V., Nawale, A.B., Lalla, N.P., Mishra, R., Sathe, V.G., Bhoraskar, S.V., Das, A.K.: A novel approach towards selective bulk synthesis of few-layer graphenes in an electric arc. J. Phys. D: Appl. Phys. 42(11), 115201 (2009). doi:10.1088/0022-3727/42/11/115201

45. Rollings, E., Gweon, G.-H., Zhou, S.Y., Mun, B.S., McChesney, J.L., Hussain, B.S., Fedorov, A.V., First, P.N., First, P.N., de Heer, W.A., Lanzar, A.: Synthesis and characterization of atomically thin graphite films on a silicon carbide substrate. J. Phys. Chem. Solids 67(9-10), 2172-2177 (2006). doi:10.1016/ j.jpcs.2006.05.010

46. Heer, D.W.A., Berger, C., Wu, X., First, P.N., Conrad, E.H., Li, X., Li, T., Sprinkle, M., Hass, J., Sadowski, M.L., Potemski, M., Martinez, G.: Epitaxial graphene. Solid State Commun. 143(1-2), 92-100 (2007). doi:10.1016/j.ssc.2007.04.023

47. Alexander, M., Oleg, P.: Density functional study of graphene overlayers on SiC. Phys. Status Solidi B 245(7), 1425-1435 (2008). doi:10.1002/pssb.200844031

48. Ni, Z.H., Chen, W., Fan, X.F., Kuo, J.L., Yu, T., Wee, A.T.S., Shen, Z.X.: Raman spectroscopy of epitaxial graphene on a SiC substrate. Phys. Rev. B: Condens. Matter 77, 115416 (2008). doi:10.1103/PhysRevB.77.115416

49. Sutter, P.W., Flege, J.-I., Sutter, E.A.: Epitaxial graphene on ruthenium. Nature Mater. 7, 406-411 (2008). doi:10.1038/ nmat2166

50. Seyller, T., Bostwick, A., Emtsev, K.V., Horn, K., Ley, L., McChesney, J.L., Ohta, T., Riley, J.D., Rotenberg, E., Speck, F.: Epitaxial graphene: a new material. Phys. Status Solidi B 245(7), 1436-1446 (2008). doi:10.1002/pssb.200844143

51. Sprinkle, M., Soukiassian, P., de Heer, W.A., Berger, C., Conrad, E.H.: Epitaxial graphene: the material for graphene electronics. Phys. Status Solidi RRL 3(6), A91-A94 (2009). doi:10. 1002/pssr.200903180

52. Hirsch, A.: Unzipping carbon nanotubes: a peeling method for the formation of graphene nanoribbons. Angew. Chem. Int. Ed. 48(36), 6594-6596 (2009). doi:10.1002/anie.200902534

53. Kim, C.-D., Min, B.-K., Jung, W.-S.: Preparation of graphene sheets by the reduction of carbon monoxide. Carbon 47(6), 1610-1612 (2009). doi:10.1016/j.carbon.2009.02.025

54. Bourlinos, A.B., Georgakilas, V., Zboril, R., Steriotis, T.A., Stubos, A.: Liquid-phase exfoliation of graphite towards solubilized graphenes. Small 5(16), 1841-1845 (2009). doi:10.1002/ smll.200900242

55. Hernandez, Y., Nicolosi, V., Lotya, M., Blighe, F.M., Sun, Z., De, S., McGovern, I.T., Holland, B., Byrne, M., Gun'Ko, Y.K., Boland, J.J., Niraj, P., Duesberg, G., Krishnamurthy, S., Goodhue, R., Hutchison, J., Scardaci, V., Ferrari, A.C., Coleman, J.N.: High-yield production of graphene by liquid-phase exfoliation of graphite. Nature Nanotechnol 3, 563-568 (2008). doi:10.1038/nnano.2008.215

56. Liu, N., Luo, F., Wu, H., Liu, Y., Zhang, C., Chen, J.: one-step ionic-liquid-assisted electrochemical synthesis of ionic-liquidfunctionalized graphene sheets directly from graphite. J. Adv. Funct. Mater. 18(10), 1518-1525 (2008). doi:10.1002/adfm. 200700797
57. Behabtu, N., Lomeda, J.R., Green, M.J., Higginbotham, A.L., Sinitskii, A., Kosynkin, D.V., Tsentalovich, D., Parra-Vasquez, A.N.G., Schmidt, J., Kesselman, E., Cohen, Y., Talmon, Y., Tour, J.M., Pasquali, M.: Spontaneous high-concentration dispersions and liquid crystals of grapheme. Nature Nanotechnol. 5, 406-411 (2010). doi:10.1038/nnano.2010.86

58. Rao C. N. R., Maitra U. and Matte H. S. S. R.; Synthesis, Characterization, and Selected Properties of Graphene. In: Rao C. N. R and Sood A. K. (eds) Graphene: Synthesis, Properties, and Phenomena, First Edition. Published 2013 by Wiley-VCH Verlag GmbH and Co. KGaA

59. Hiura, H., Ebbesen, T.W., Fujita, J., Tanigaki, K., Takada, T.: Role of sp3 defect structures in graphite and carbon nanotubes. Nature 367, 148-151 (1994). doi:10.1038/367148a0

60. Ebbesen, T.W., Hiura, H.: Graphene in 3-dimensions: towards graphite origami. Adv. Mater. 7(6), 582-586 (1995). doi:10. 1002/adma.19950070618

61. Bernhardt, T.M., Kaiser, B., Rademann, K.: Formation of superperiodic patterns on highly oriented pyrolytic graphite by manipulation of nanosized graphite sheets with the STM tip. Surf. Sci. 408(1-3), 86-94 (1998). doi:10.1016/S0039-6028(98)00152-6

62. Lu, X., Yu, M., Huang, H., Ruoff, R.S.: Tailoring graphite with the goal of achieving single sheets. Nanotechnology 10(3), 269 (1999). doi:10.1088/0957-4484/10/3/308

63. Roy, H.V., Kallinger, C., Sattler, K.: Manipulation of graphitic sheets using a tunneling microscope. J. Appl. Phys. 83, 4695 (1998). doi:10.1063/1.367257

64. Ci, L.J., Song, L., Jariwala, D., Elias, A.L., Gao, W., Terrones, M., Ajayan, P.M.: Graphene shape control by multistage cutting and transfer. Adv. Mater. 21(44), 4487-4491 (2009). doi:10. 1002/adma.200900942

65. Liang, X., Chang, A.S.P., Zhang, Y., Harteneck, B.D., Choo, H., Olynick, D.L., Cabrini, S.: Electrostatic force assisted exfoliation of prepatterned few-layer graphenes into device sites. Nano Lett. 9(1), 467-472 (2008). doi:10.1021/nl803512z

66. Liang, X., Fu, Z., Chou, S.Y.: Graphene transistors fabricated via transfer-printing in device active-areas on large wafer. Nano Lett. 7(12), 3840-3844 (2007). doi:10.1021/n1072566s

67. Chen, J.-H., Ishigami, M., Jang, C., Hines, D.R., Fuhrer, M.S., Williams, E.D.: Printed graphene circuits. Adv. Mater. 19(21), 3623-3627 (2007). doi:10.1002/adma.200701059

68. Vincent, H., Bendiab, N., Rosman, N., Ebbesen, T., Delacour, C., Bouchiatand, v: Large and flat graphene flakes produced by epoxy bonding and reverse exfoliation of highly oriented pyrolytic graphite. Nanotechnology 19(45), 455601 (2008). doi:10. 1088/0957-4484/19/45/455601

69. Liu, L.-H., Yan, M.: Simple method for the covalent immobilization of graphene. Nano Lett. 9(9), 3375-3378 (2009). doi:10. 1021/n1901669h

70. Song, L., Ci, L., Gao, W., Ajayan, P.M.: Transfer printing of graphene using gold film. ACS Nano 3(6), 1353-1356 (2009). doi:10.1021/nn9003082

71. Ni, Z.H., Wang, H.M., Kasim, J., Fan, H.M., Yu, T., Wu, Y.H., Feng, Y.P., Shen, Z.X.: Graphene thickness determination using reflection and contrast spectroscopy. Nano Lett. 7(9), 2758-2763 (2007). doi:10.1021/n1071254m

72. Ferrari, A.C., Meyer, J.C., Scardaci, V., Casiraghi, C., Lazzeri, M., Mauri, F., Piscanec, S., Jiang, D., Novoselov, K.S., Roth, S., Geim, A.K.: Raman spectrum of graphene and graphene layers. Phys Rev Lett 97(18), 187401 (2006). doi:10.1103/PhysRevLett. 97.187401

73. Ferrari, A.C.: Raman spectroscopy of graphene and graphite: disorder, electron-phonon coupling, doping and nonadiabatic effects. Solid State Commun. 143(1-2), 47-57 (2007). doi:10. 1016/j.ssc.2007.03.052 
74. Ni, Z., Wang, Y., Yu, T., Shen, Z.: Raman spectroscopy and imaging of graphene. Nano Research 1(4), 273-291 (2008). doi:10.1007/s12274-008-8036-1

75. Casiraghi, C., Hartschuh, A., Lidorikis, E., Qian, H., Harutyunyan, H., Gokus, T., Novoselov, K.S., Ferrari, A.C.: Rayleigh imaging of graphene and graphene layers. Nano Lett. 7(9), 2711-2717 (2007)

76. Park, S., Lee, K.-S., Bozoklu, G., Cai, W., Nguyen, S.T., Ruoff, R.S.: Graphene oxide papers modified by divalent ions-enhancing mechanical properties via chemical cross-linking. ACS Nano 2(3), 572-578 (2008). doi:10.1021/nn700349a

77. Li, D., Muller, M.B., Gilje, S., Kaner, R.B., Wallace, G.G.: Processable aqueous dispersions of graphene nanosheets. Nature Nanotech. 3, 101-105 (2008). doi:10.1038/nnano.2007.451

78. Xu, Y., Bai, H., Lu, G., Li, C., Shi, G.: Flexible graphene films via the filtration of water-soluble noncovalent functionalized graphene sheets. J. Am. Chem. Soc. 130(18), 5856-5857 (2008). doi:10.1021/ja800745y

79. Park, S., An, J.H., Piner, R.D., Jung, I., Yang, D.X., Velamakanni, A., Nguyen, S.T., Ruoff, R.S.: Aqueous suspension and characterization of chemically modified graphene sheets. Chem. Mater. 20(21), 6592-6594 (2008). doi:10.1021/ $\mathrm{cm} 801932 \mathrm{u}$

80. Chen, H., Muller, M.B., Gilmore, K.J., Wallace, G.G., Li, D.: Mechanically strong, electrically conductive, and biocompatible graphene paper. Adv. Mater. 20(18), 3557-3561 (2008). doi:10. 1002/adma.200800757

81. Stoller, M.D., Park, S.J., Zhu, Y.W., An, J.H., Ruoff, R.S.: Graphene-based ultracapacitors. Nano Lett. 8(10), 3498-3502 (2008). doi:10.1021/n1802558y

82. Wang, X., Zhi, L., Mullen, K.: Transparent, conductive graphene electrodes for dye-sensitized solar cells. Nano Lett. 8(1), 323-327 (2008). doi:10.1021/n1072838r

83. Brodie, B.C.: Sur le poids atomique du graphite. Ann. Chim. Phys. 59, 466-472 (1860)

84. Hummers, W.S., Offeman, R.E.: Preparation of graphitic oxide. J. Am. Chem. Soc. 80(6), 1339 (1958). doi:10.1021/ ja01539a017

85. Staudenmaier, L.: Verfahren zur Darstellung der Graphitsäure. Eur. J. Inorg. Chem. 31(2), 1481-1487 (1898). doi:10.1002/cber. 18980310237

86. Wu, Y.H., Yu, T., Shen, Z.X.: Two-dimensional carbon nanostructures: fundamental properties, synthesis, characterization, and potential applications. J. Appl. Phys. 108, 071301 (2010). doi:10.1063/1.3460809

87. Marcano, D.C., Kosynkin, D.V., Berlin, J.M., Sinitskii, A., Sun, Z., Slesarev, A., Alemany, L.B., Lu, W., Tour, J.M.: Improved synthesis of graphene oxide. ACS Nano 4(8), 4806-4814 (2010). doi:10.1021/nn1006368

88. Park, S., An, J., Jung, I., Piner, R.D., An, S.J., Li, X., Velamakanni, A., Ruoff, R.S.: Colloidal suspensions of highly reduced graphene oxide in a wide variety of organic solvents. Nano Lett. 9(4), 1593-1597 (2009). doi:10.1021/n1803798y

89. Allen, M.J., Tung, V.C., Kaner, R.B.: Honeycomb carbon: a review of graphene. Chem. Rev. 110(1), 132-145 (2009). doi:10.1021/cr900070d

90. Tung, V.C., Allen, M.J., Yang, Y., Kaner, R.B.: High-throughput solution processing of large-scale graphene. Nat. Nanotechnol. 4, 25-29 (2009). doi:10.1038/nnano.2008.329

91. Paredes, J.I., Villar-Rodil, S., Marti'nez-Alonso, A., Tasco'n, J.M.D.: "Graphene oxide dispersions in organic solvents". Langmuir 24(19), 10560-10564 (2008). doi:10.1021/la801744a

92. Green, A.A., Hersam, M.C.: Emerging methods for producing monodisperse graphene dispersions. J Phys Chem Lett 1(2), 544-549 (2009). doi:10.1021/jz900235f
93. Green, A.A., Hersam, M.C.: Solution phase production of graphene with controlled thickness via density differentiation. Nano Lett. 9(12), 4031-4036 (2009). doi:10.1021/n1902200b

94. Wu, J., Pisula, W., Müllen, K.: Graphenes as potential material for electronics. Chem. Rev. 107(3), 718-747 (2007). doi:10. 1021/cr068010r

95. Cai, J., Ruffieux, P., Jaafar, R., Bieri, M., Braun, T., Blankenburg, S., Matthias, M., Seitsonen, A.P., Moussa, S., Feng, X., Müllen, K., Fasel, R.: Atomically precise bottom-up fabrication of graphene nanoribbons. Nature 466, 470-473 (2010). doi:10. 1038/nature09211

96. Yan, X., Cui, X., Binsong, L., Liang-shi, L.: Large, solutionprocessable graphene quantum dots as light absorbers for photovoltaics. Nano Lett. 10(5), 1869-1873 (2010). doi:10.1021/ nl101060h

97. Zhi, L., Mullen, K.A.: A bottom-up approach from molecular nanographenes to unconventional carbon materials. J. Mater. Chem. 18, 1472-1484 (2008). doi:10.1039/B717585J

98. Hamilton, C.E., Lomeda, J.R., Sun, Z., Tour, J.M., Barron, A.R.: High-yield organic dispersions of unfunctionalized graphene. Nano Lett. 9(10), 3460-3462 (2009). doi:10.1021/n19016623

99. ONeill, A., Khan, U., Nirmalraj, P.N., Boland, J., Coleman, J.N.: Graphene dispersion and exfoliation in low boiling point solvents. J.Phys. Chem.C 115(13), 5422-5428 (2011). doi:10.1021/ jp110942e

100. Hernandez, Y., Lotya, M., Rickard, D., Bergin, S.D., Coleman, J.N.: Measurement of multicomponent solubility parameters for graphene facilitates solvent discovery. Langmuir 26(5), 3208-3213 (2009). doi:10.1021/la903188a

101. Qian, M., Zhoul, Y.S., Gao, Y., Parkl, J.B., Feng, T., Huang, S.M., Sun, Z., Jiang, L., Lul, Y.F.: Formation of graphene sheets through laser exfoliation of highly ordered pyrolytic graphite. Appl. Phys. Lett. 98, 173108 (2011). doi:10.1063/1.3584021

102. Shin, H.-J., Kim, K.K., Benayad, A., Yoon, S.-M., Park, H.K., Jung, I.-S., Jin, M.H., Jeong, H.-K., Kim, J.M., Choi, J.-Y., Lee, Y.H.: Efficient reduction of graphite oxide by sodium borohydride and its effect on electrical conductance. Adv. Funct. Mater. 19(12), 1987-1992 (2009). doi:10.1002/adfm.200900167

103. Pham, V.H., Cuong, T.V., Nguyen-Phan, T.-D., Pham, H.D., Kim, E.J., Hur, S.H., Shin, E.W., Kim, S., Chung, J.S.: One-step synthesis of superior dispersion of chemically converted graphene in organic solvents. Chem. Commun. 46, 4375-4377 (2010). doi:10.1039/C0CC00363H

104. Zhou, X., Zhang, J., Wu, H., Yang, H., Zhang, J., Guo, S.: Reducing graphene oxide via hydroxylamine: a simple and efficient route to graphene. J. Phys. Chem. C 115(24), 11957-11961 (2011). doi:10.1021/jp202575j

105. Zhu, C., Guo, S., Fang, Y., Dong, S.: Reducing sugar: new functional molecules for the green synthesis of graphene nanosheets. ACS Nano 4(4), 2429-2437 (2010). doi:10.1021/nn1002387

106. Zhang, J., Yang, H., Shen, G., Cheng, P., Zhang, J., Guo, S.: Reduction of graphene oxide viaL-ascorbic acid. Chem. Commun. 46, 1112-1114 (2010). doi:10.1039/B917705A

107. Wang, G., Yang, J., Park, J., Gou, X., Wang, B., Liu, H., Yao, J. Facile synthesis and characterization of graphene nanosheets. J. Phys. Chem. 112(22), 8192-8195 (2008). doi:10.1021/ jp710931h

108. Fan, X., Peng, W., Li, Y., Li, X., Wang, S., Zhang, G., Zhang, F.: Deoxygenation of exfoliated graphite oxide under alkaline conditions: a green route to graphene preparation. Adv. Mater. 20(23), 4490-4493 (2008). doi:10.1002/adma.200801306

109. Amarnath, C.A., Hong, C.E., Kim, N.H., Ku, B.-C., Kuila, T., Lee, J.H.: Efficient synthesis of graphene sheets using pyrrole as a reducing agent. Carbon 49(11), 3497-3502 (2011). doi:10. 1016/j.carbon.2011.04.048 
110. Stankovich, S., Piner, R.D., Nguyen, S.T., Ruoff, R.S.: Synthesis and exfoliation of isocyanate-treated graphene oxide nanoplatelets. Carbon 44(15), 3342-3347 (2006). doi:10.1016/j.carbon. 2006.06.004

111. Guo, H.-L., Wang, X.-F., Qian, Q.-Y., Wang, F.-B., Xia, X.-H.: A green approach to the synthesis of graphene nanosheets. ACS Nano 3(9), 2653-2659 (2009). doi:10.1021/nn900227d

112. Sundaram, R.S., Ǵomez-Navarro, C., Balasubramanian, K., Burghard, M., Kern, K.: Electrochemical modification of graphene. Adv. Mater. 20(16), 3050-3053 (2008). doi:10.1002/ adma. 200800198

113. Compton, O.C., Jain, B., Dikin, D.A., Abouimrane, A., Amine, K., Nguyen, S.T.: Chemically active reduced graphene oxide with tunable C/O ratios. ACS Nano 5(6), 4380-4391 (2011). doi:10.1021/nn1030725

114. McAllister, M.J., Li, J.L., Adamson, D.H., Schniepp, H.C., Abdala, A.A., Liu, J., Alonso, M.H., Milius, D.L., Car, R., Robert, K., Prud'homme, R.K., Aksay, I.A.: Single sheet functionalized graphene by oxidation and thermal expansion of graphite. Chem. Mater. 19(18), 4396-4404 (2007). doi:10.1021/ cm0630800

115. Parades, J.I., Villar-Rodil, S., Mart́nez-Alonso, A., Tasćon, J.M.D.: Graphene oxide dispersions in organic solvents. Langmuir 24(19), 10560-10564 (2008). doi:10.1021/la801744a

116. Dubin, S., Gilje, S., Wang, K., Tung, V.C., Cha, K., Hall, A.S., Farrar, J., Varshneya, R., Yang, Y., v, R.B.: A one-step, solvothermal reduction method for producing reduced graphene. ACS Nano 4(7), 3845-3852 (2010). doi:10.1021/nn100511a

117. Xu, Y.X., Bai, H., Lu, G.W., Li, C., Shi, G.Q.: Flexible graphene films via the filtration of water-soluble noncovalent functionalized graphene sheets. J. Am. Chem. Soc. 130(18), 5856-5857 (2008). doi:10.1021/ja800745y

118. Li, X.L., Wang, X.R., Zhang, L., Lee, S.W., Dai, H.J.: Chemically derived, ultrasmooth graphene nanoribbon semiconductors. Science 319(5867), 1229-1232 (2008). doi:10.1126/ science. 1150878

119. Li, X.L., Zhang, G.Y., Bai, X.D., Sun, X., Wang, X., Wang, E., Dai, H.: Highly conducting graphene sheets and LangmuirBlodgett films. Nat. Nanotechnol. 3(9), 538-542 (2008). doi:10. 1038/nnano.2008.210

120. W, M., Joonsuk, O., Ghosh, T., Hong, S., Nam, G., Hwang, T., Nam, J.-D.: An interleaved porous laminate composed of reduced graphene oxide sheets and carbon black spacers by in situ electrophoretic deposition. RSC Adv 4(1), 3284-3292 (2014). doi:10.1039/C3RA45979A

121. Xiao Huang, Shaozhou Li, Yizhong Huang,Shixin Wu, Xiaozhu Zhou, Shuzhou Li, Chee Lip Gan, Freddy Boey, Chad A. Mirkin and Hua Zhang; "Synthesis of hexagonal close-packed gold nanostructures". Nature Communications 2, Article number: 292. http://dx.doi.org/10.1038/ncomms1291

122. Guo, S., Dong, S., Wang, E.: Three-dimensional Pt-on-Pd bimetallic nanodendrites supported on graphene nanosheet: facile synthesis and used as an advanced nanoelectrocatalyst for methanol oxidation. ACS Nano 4(1), 547-555 (2010). doi:10. $1021 / \mathrm{nn} 9014483$

123. Choucair, M., Thordarson, P., Stride, J.A.: Gram-scaleproduction of graphene based on solvothermal synthesis andsonication. Nat. Nanotechnol. 4(1), 30-33 (2009). doi:10.1038/nnano.2008.365

124. Kim, K.S., Zhao, Y., Jang, H., Lee, S.Y., Kim, J.M., Kim, K.S., Ahn, J.-H., Kim, P., Choi, J.-Y., Hong, B.H.: Large-scale pattern growth of graphene films for stretchable transparent electrodes. Nature 457, 706-710 (2009). doi:10.1038/nature07719

125. Kwon, S.-Y., Ciobanu, C.V., Petrova, V., Shenoy, V.B., Bareno, J., Gambin, V., Petrov, I., Kodambaka, S.: Growth of semiconducting graphene on palladium. Nano Lett. 9(12), 3985-3990 (2009). doi:10.1021/nl902140j
126. Coraux, J., N`Diaye, A.T., Busse, C., Michely, T.: Structural coherency of graphene on $\operatorname{Ir}(111)$ ". Nano Lett. 8(2), 565-570 (2008). doi: $10.1021 / \mathrm{n} 10728874$

127. Wei, D., Liu, Y., Wang, Y., Zhang, H., Huang, L., Yu, G.: Synthesis of N-doped graphene by chemical vapor deposition and its electrical properties. Nano Lett. 9(5), 1752-1758 (2009). doi:10.1021/n1803279t

128. Yu, Q., Lian, J., Siriponglert, S., Li, H., Chen, Y.P., Pei, S-.S.: Graphene segregated on Ni surfaces and transferred to insulators. Appl. Phys. Lett. 93(11), 113103 (2008). doi:10.1063/1. 2982585

129. Obraztsov, A.N., Obraztsova, E.A., Tyurnina, A.V., Zolotukhin, A.A.: Chemical vapor deposition of thin graphite films of nanometer thickness. Carbon 45(10), 2017-2021 (2007). doi:10. 1016/j.carbon.2007.05.028

130. Karu, A.E., Beer, M.: Pyrolytic formation of highly crystalline graphite films. J. Appl. Phys. 37, 2179 (1966). doi:10.1063/1. 1708759

131. Perdereau, J., Rhead, G.E.: LEED studies of adsorption on vicinal copper surfaces. Surf Science 24(2), 555-571 (1971). doi:10.1016/0039-6028(71)90281-0

132. Kholin, N.A., Rut'kov, E.V., Tontegode, A.Y.: The nature of the adsorption bond between graphite islands and iridium surface. Surf. Sci. 139(1), 155-172 (1984). doi:10.1016/00396028(84)90014-1

133. Gall, N.R., Rut'kov, E.V., Tontegode, A.Y.: Intercalation of nickel atoms under two-dimensional graphene film on (111)Ir. Carbon 38(5), 663-667 (2000). doi:10.1016/S00086223(99)00135-9

134. Katsnelson, I.M.: Graphene: Carbon in two dimensions. Mater

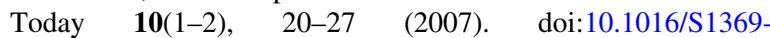
7021(06)71788-6

135. Geim, A.K., Kim, P.: Carbon wonderland. Sci Am 298(4), 90-97 (2008). doi:10.1038/scientificamerican0408-90

136. Dreyer, D.R., Park, S., Bielawski, C.W., Ruoff, R.S.: The chemistry of graphene oxide. Chem. Soc. Rev. 39(1), 228-240 (2010). doi:10.1039/B917103G

137. Somani, P.R., Somani, S.P., Umeno, M.: Planar nano-graphenes from camphor by CVD. Chem. Phys. Lett. 430(1-3), 56-59 (2006). doi:10.1016/j.cplett.2006.06.081

138. Verma, V.P., Das, S., Lahiri, I., Choi, W.: Large-area graphene on polymer film for flexible and transparent anode in field emission device. Appl Phys Lett 96, 20 (2010). doi:10.1063/1. 3431630

139. Bae, S., Kim, H., Lee, Y., et al.: Roll-to-roll production of 30-inch graphene films for transparent electrodes. Nat. Nanotechnol. 5(8), 574-578 (2010). doi:10.1038/nnano.2010.132

140. Li, X., et al.: Large-area graphene single crystals grown by lowpressure chemical vapor deposition of methane on copper. J. Am. Chem. Soc. 133, 2816 (2011). doi:10.1021/ja109793s

141. Geim, A.K.: Graphene: status and prospects. Sci 324, 1530-1534 (2009). doi:10.1126/science.1158877

142. Li, X., Cai, W., Colombo, L., Ruoff, R.S.: Evolution of graphene growth on $\mathrm{Ni}$ and $\mathrm{Cu}$ by carbon isotope labeling. Nano Lett. 9, 4268-4272 (2009). doi:10.1021/n1902515k

143. Luo, Z., Lu, Y., Singer, D.W., Berck, M.E., Somers, L.A., Goldsmith, B.R., Johnson, A.T.C.: Effect of substrate roughness and feedstock concentration on growth of wafer-scale graphene at atmospheric pressure. Chem. Mater. 23, 1441-1447 (2011). doi: $10.1021 / \mathrm{cm} 1028854$

144. Liu, W., Li, H., Xu, C., Khatami, Y., Banerjee, K.: Synthesis of high-quality monolayer and bilayer graphene on copper using chemical vapor deposition. Carbon 49, 4122-4130 (2011). doi:10.1016/j.carbon.2011.05.047

145. Kim, H., Mattevi, C., Calvo, M.R., Oberg, J.C., Artiglia, L., Agnoli, S., Hirjibehedin, C.F., Chhowalla, M., Saiz, E.: 
Activation energy paths for graphene nucleation and growth on Cu. ACS Nano 6, 3614-3623 (2012). doi:10.1021/nn3008965

146. Congqin, M., Churan, Z., Owen, L., Ya-Hong, X.: Chemical vapor deposition of graphene. In: Mikhailov, S. (ed.) Physics and Applications of Graphene-Experiments, pp. 37-54. Rijeka, InTech (2011)

147. Li, X., Magnuson, C.W., Venugopal, A., et al.: Graphene films with large domain size by a two-step chemical vapor deposition process. Nano Lett. 10(11), 4328-4334 (2010). doi:10.1021/ $\mathrm{nl} 101629 \mathrm{~g}$

148. V Yu, E Whiteway, J Maassen, and M Hilke, "Raman spectroscopy of the internal strain of a graphene layer grown on copper tuned by chemical vapor deposition," Phys. Rev. B 2011, Vol. 84, No. 20, article 205407. 10.1103/PhysRevB.84.205407

149. Petrone. N., C. R. Dean, Meric. I., A. M. Zande, Pinshane Y. H., Wang. L., David Muller, K. L. Shepard, and Hone. J.;"Chemical Vapor Deposition-Derived Graphene with Electrical Performance of Exfoliated Graphene";Nano Lett (2012) Vol.12, pp.2751. http://dx.doi.org/10.1021/n1204481s

150. Zhengzong. S., Yan. Z., Yao.J.,Beitler. E., Zhu. Y.\& James M. Tour., "Growth of graphene from solid carbon sources"; Nature (2010) Vol.468, pp.549. http://dx.doi.org/10.1038/nature09579

151. Li, Z., Wu, P., Wang, C., Fan, X., Zhang, W., Zhai, X., Zeng, C., Li, Z., Yang, J., Hou, J.: Low-Temperature growth of graphene by chemical vapor deposition using solid and liquid carbon sources. ACS NANO 5, 3385 (2011). doi:10.1021/nn200854p

152. Reina, A., Thiele, S., Jia, X.T., et al.: Growth of large-area single- and bi-layer graphene by controlled carbon precipitation on polycrystalline Ni surfaces. Nano Research 2(6), 509-516 (2009). doi:10.1007/s12274-009-9059-y

153. Addou, R., Dahal, A., Sutter, P., Batzill, M.: Monolayer graphene growth on $\mathrm{Ni}(111)$ by low temperature chemical vapor deposition. Appl. Phys. Lett. 100, 021601 (2012). doi:10.1063/1. 3675481

154. Veríssimo C., Moshkalyov S. A., Ramos A. C. S., Gonçalves J. L., Alves O. L. and Swart J. W.; Different carbon nanostructured materials obtained in catalytic chemical vapor deposition. J. Braz. Chem. Soc. 2006, Vol. 17, No. 6. http://dx.doi.org/10. 1590/S010350532006000600009

155. Shang, N.G., Papakonstantinou, P., McMullan, M., et al.: Catalyst-free efficient growth, orientation and biosensing properties of multilayer graphene nanoflake films with sharp edge planes. Adv. Funct. Mater. 18(21), 3506-3514 (2008). doi:10.1002/ adfm. 200800951

156. Obraztsov, A.N., Zolotukhin, A.A., Ustinov, A.O., Volkov, A.P., Svirko, Y., Jefimovs, K.: DC discharge plasma studies for nanostructured carbon CVD. Diam. Relat. Mater. 12(3-7), 917-920 (2003). doi:10.1016/S0925-9635(02)00338-2

157. Wang, J.J., Zhu, M.Y., Outlaw, R.A., Zhao, X., Manos, D.M., Holloway, B.C.: Synthesis of carbon nanosheets by inductively coupled radio-frequency plasma enhanced chemical vapor deposition. Carbon 42(14), 2867-2872 (2004). doi:10.1016/j. carbon.2004.06.035

158. Chhowalla, M., Teo, K.B.K., Ducati, C., Rupesinghe, N.L., Amaratunga, G.A.J., Ferrari, A.C., Roy, D., Robertson, J., Milne, W.I.: Growth process conditions of vertically aligned carbon nanotubes using plasma enhanced chemical vapor deposition. J Appl Phys 90, 5308 (2001). doi:10.1063/1.1410322

159. Teo, K.B.K., Lee, S.-B., Chhowalla, M., Semet, V., Binh, V.T., Groening, O., Castignolles, M., Loiseau, A., Pirio, G., Legagneux, P., Pribat, D., Hasko, D.G., Ahmed, H., Amaratunga, G.A.J., Milne, W.I.: Plasma enhanced chemical vapour deposition carbon nanotubes/nanofibres-how uniform do they grow? Nanotechnology 14, 204 (2001). doi:10.1088/0957-4484/14/2/ 321
160. Hofmann, S., Csányi, G., Ferrari, A.C., Payne, M.C., Robertson, J.: Surface diffusion: the low activation energy path for nanotube growth. Phys. Rev. Lett. 95, 036101 (2005). doi:10.1103/ PhysRevLett.95.036101

161. Boskovic, B.O., Stolojan, V., Khan, R.U.A., Haq, S., Ravi, S., Silva, P.: Large-area synthesis of carbon nanofibres at room temperature. Nature Mater 1, 165 (2002). doi:10.1038/nmat755

162. Casiraghi, C., Ferrari, A.C., Ohr, R., Flewitt, A.J., Chu, D.P., Robertson, J.: Dynamic roughening of tetrahedral amorphous carbon. Phys. Rev. Lett. 91, 226104 (2003)

163. Moseler, M., Gumbsch, P., Casiraghi, C., Ferrari, Andrea C., Robertson, J.: The ultrasmoothness of diamond-like carbon surfaces. Science 309(5740), 1545-1548 (2005)

164. Lee, J. et al. RF performance of pre-patterned locally embeddedback-gate graphene device. In: 2010 International Electron Devices Meeting-Technical Digest, IEEE, New York, (2010)

165. Van Bommel, A.J., Crombeen, J.E., Van Tooren, A.: LEED and Auger electron observations of the $\mathrm{SiC}(0001)$ surface. Surf. Sci. 48(2), 463-472 (1975). doi:10.1016/0039-6028(75)90419-7

166. De Heer W., The development of epitaxial graphene for $21 \mathrm{st}$ century electronics; ar Xiv: 1012. 1644v1

167. Heera, W.A., Bergera, C., Ruana, M., Sprinklea, M., Lia, X., Hua, Y., Zhanga, B., Hankinsona, J., Conrada, E.: Large area and structured epitaxial graphene produced by confinement controlled sublimation of silicon carbide. PNAS 108, 16900 (2011). doi:10.1073/pnas.1105113108

168. Hass, J., Fengl, R., Li, T., Li, X., Zong, Z., de Heer, W.A., First, P.N., Conrad, E.H., Jeffrey, C.A., Berger, C.: Highly ordered graphene for two dimensional electronics. Appl. Phys. Lett. 89, 143106 (2006). doi:10.1063/1.2358299

169. Hass, J., Millán-Otoya, J.E., First, P.N., Conrad, E.H.: Interface structure of epitaxial graphene grown on $4 \mathrm{H}-\mathrm{SiC}(0001)$. Phys Rev B 78, 205424 (2008). doi:10.1103/PhysRevB.78.205424

170. Forbeaux, I., Themlin, J.-M., Charrier, A., Thibaudau, F., Debever, J.-M.: Solid-state graphitization mechanisms of silicon carbide 6H-SiC polar faces. Appl. Surf. Sci. 162, 406 (2000). doi:10.1016/S0169-4332(00)00224-5

171. Hass, J., Jeffrey, C.A., Feng, R., Li, T., Li, X., Song, Z., Berger, C., de Heer, W.A., First, P.N., Conrad, E.H.: Highly-ordered graphene for two dimensional electronics. J Appl Phys 92, 2479 (2002)

172. Emtsev, K.V., Speck, F., Seyller, Th, Ley, L., Riley, J.D.: Interaction, growth, and ordering of epitaxial graphene on $\mathrm{SiC}\{0001\}$ surfaces: a comparative photoelectron spectroscopy study. Phys Rev B 77, 155303 (2008)

173. Davis, R.F., et al.: Thin film deposition and microelectronic and optoelectronic. Proc. IEEE 79, 677 (1991)

174. Kedzierski, J., Hsu, P.-L., Healey, P., Wyatt, P., Keast, C., Sprinkle, M., Berger, C., Heer, W.D.: Epitaxial graphene transistors on $\mathrm{SiC}$ substrates. IEEE Trans. Electron Devices 55, 2078 (2008). doi:10.1109/TED.2008.926593

175. Y.-M. Lin, C. Dimitrakopoulos, K. A. Jenkins, D. B. Farmer, H.Y. Chiu, A. Grill, Ph. Avouris., 100-GHz Transistors from Wafer-Scale Epitaxial Graphene, Sci (2010) Vol.327, pp.662. http://dx.doi.org/10.1126/science.1184289

176. Schwierz, F.: Graphene transistors. Nature Nanotech 5, 487 (2010). doi:10.1038/nnano.2010.89

177. Novoselov, K.S., Geim, A.K., Morozov, S.V., Jiang, D., Katsnelson, M.I., Grigorieva, I.V., Firsov, A.A.: Two-dimensional gas of massless Dirac fermions in graphene. Nature 438, 197 (2005). doi:10.1038/nature04233

178. Chen, Z.H., Lin, Y.M., Rooks, M.J., Avouris, P.: Graphene nano-ribbon electronics. Phys. E-Low-Dimens. Syst. Nanostructures 40(2), 228-232 (2007). doi:10.1016/j.physe.2007.06. 020 
179. Cano-Marquez, A.G., Rodriguez-Macias, F.J., Campos-Delgado, J., Espinosa-González, G.C., Tristán-López, F., RamírezGonzález, D., Cullen, A.D., Smith, J.D., Terrones, M., VegaCantú, I.Y.: Ex-MWNTs:Graphene sheets and ribbons produced by lithium intercalation and exfoliation of carbon nanotubes. Nano Letters 9(4), 1527-1533 (2009). doi:10.1021/n1803585s

180. Subrahmanyam, K.S., Panchakarla, L.S., Govindaraj, A., Rao, C.N.R.: Simple method of preparing graphene flakes by an arcdischarge method. J. Phys. Chem.C 113, 4257 (2009). doi:10. 1021/jp900791y

181. Panchakarla, L.S., Govindaraj, A., Rao, C.N.R.: Boron- and nitrogen-doped carbon nanotubes and graphene. InorgChim. Acta 363, 4163 (2009). doi:10.1016/j.ica.2010.07.057

182. Wu, Z.-S., Ren, W., Gao, L., Zhao, J., Chen, Z., Liu, B., Tang, D., Yu, B., Jiang, C., Cheng, H.-M.: Synthesis of graphene sheets with high electrical conductivity and good thermal stability by hydrogen arc discharge exfoliation. ACS Nano 3, 411 (2009). doi:10.1021/nn900020u

183. K. S. Subrahmanyam, S. R.C. Vivekchand, A. Govindaraj,and C. N.R. Rao, "A study of graphenes prepared by different methods: characterization, properties and solubilization,"Journal of Materials Chemistry, vol. 18, no. 13, pp. 1517-1523. http://dx.doi.org/10.1039/B716536F

184. Rao, C.N.R., Subrahmanyam, K.S., Ramakrishna Matte, H.S.S., Abdulhakeem, B., Govindaraj, A., Das, B., Kumar, P., Ghosh, A., Late, D.J.: A study of the synthetic methods and properties of graphenes. Sci. Technol. Adv. Mater. 11, 054502 (2010). doi:10.1088/1468-6996/11/5/054502

185. Zhiyong, W., Nan, L., Zujin, S., Zhennan, G.: Low-cost and large-scale synthesis of graphene nanosheets by arc discharge in air. Nanotechnology 21, 175602 (2010). doi:10.1088/09574484/21/17/175602

186. Bhuyan, S.A., Uddin, N., Bipasha, F.A., Islam, M., Hossain, S.S.: A review of functionalized graphene properties and its application. Int J Innov Sci Res 17(2), 303-315 (2015)

187. http://www.graphene-info.com/introduction

188. http://mediainnovationstudio.org/graphene-uav-first-for-uclanand-university-of-manchester/

189. http://dx.doi.org/10.1038/nnano.2015.110 